\title{
Why should majority voting be unfair?
}

\author{
Yves Breitmoser \\ Humboldt University Berlin
}

\author{
Jonathan H. W. Tan* \\ University of Nottingham
}

September 27, 2017

\begin{abstract}
The common use of majority rule in group decision making is puzzling. In theory, it inequitably favors the proposer, and paradoxically, it disadvantages voters further if they are inequity averse. In practice, however, outcomes are equitable. The present paper analyzes data from a novel experimental design to identify the underlying social preferences. Our experiment compares one-shot and indefinite horizon versions of random-proposer majority bargaining (the Baron-Ferejohn game) which allow us to disentangle behaviors compatible with altruism, inequity aversion, and reference dependent altruism. Most subjects are classified as reference-dependent altruists, around $10 \%$ are inequity averse. Subjects are egoistic when their payoff is below their reference point, they become efficiency concerned when satisfied, and the reference point is either the ex ante expectation or the opponent's payoff. Finally, we successfully test RDA out-of-sample on a number of distribution and bargaining games from three seminal social preference experiments.
\end{abstract}

JEL-Codes: C72, C78, D72

Keywords: bargaining, voting, experiment, social preferences, quantal response equilibrium

${ }^{*}$ We gratefully acknowledge helpful comments of two anynomous referees, the Associate Editor, Guest Editor Gregory DeAngelo, Friedel Bolle, Maria Montero, participants of the ESA World Meeting 2013, and funding of the DFG (projects BO 747/10-1 and BR 4648/1-1). The experiment was conducted at the EUV Frankfurt (Oder), Germany. Corresponding author: Jonathan Tan. Address: Nottingham University Business School, University of Nottingham, Jubilee Campus, Wollaton Road, Nottingham NG8 1BB, United Kingdom, email: jonathan.tan@nottingham.ac.uk, Phone/Fax: +44 115846 6414/6667. 


\section{Introduction}

Decisions in executive boards, committees, and parliaments are mostly reached by majority rule (Shenoy, 1980). Following Baron and Ferejohn (1989), such collective decision making processes are modeled as a random-proposer bargaining game with indefinite time horizon. In each round, a player is randomly recognized as proposer who makes a proposal which all players then vote on. The proposal is implemented if a majority votes in favor, otherwise a new round begins. This model is canonically used to study majority bargaining, with applications ranging from estimating proposer power in the US Congress (Knight, 2005) to modeling labor relations (Okada, 2011). Expected payoffs increase with power (Snyder Jr et al., 2005) and representation (Knight, 2008), but are traded off to instrumentally buy votes for pushing proposals through, e.g. in congressional elections (Levitt and Snyder Jr, 1997). Fréchette et al. (2005a) showed that experimental results resemble those of the field.

The drawback of the majority rule is made particularly obvious by the Baron-Ferejohn game. Ex ante, each of the $n$ players expects a share of $1 / n$ of the surplus. The coalition formateur needs only $n / 2$ votes to organize a majority, and thus needs to trade only half the surplus to organize a majority-keeping the rest to himself. Strikingly, Montero (2007) showed that inequity aversion (Fehr and Schmidt, 1999) further increases inequity. Given that inequity is considered an undesirable outcome in many societies, it appears unclear why groups continue to choose by majority rule. A possible explanation is that majority voting does not actually generate as much inequity in practice. As experimental evidence suggests, majority bargaining actually is reasonably equitable (Fréchette et al., 2005a,b, 2012; Montero et al., 2008; Drouvelis et al., 2010). This, however, is puzzling and raises a simple but critical question: What motivates equity in majority bargaining?

We answer this question with a systematic analysis of motives in the majority bargaining game, which is important to understand for welfare and policy analysis. For example, Knight (2005) shows that proposal power in the US Congress translates to securing project spending, and the preferences of the executive play a vital role in determining distributive outcomes (McCarty, 2000). We offer an explanation of equitable behavior and outcomes in the majority bargaining game. Ironically, the key to equity in this case seems to relate to efficiency concerns. More generally, our explanation extends the social preference theory of reference dependent altruism (RDA). RDA is known to capture behavior in the seemingly related yet strategically different demand bargaining game (Breitmoser and Tan, 2013), and below, we also show that RDA allows to capture behavior in three-player dictator 
games (Engelmann and Strobel, 2004; Bolton and Ockenfels, 2006) and simple sequential games (Charness and Rabin, 2002). Jointly, this evidence suggests that RDA may offer a reliable approach for capturing behavior in multi-player bargaining, where seminal models such as altruism and inequity aversion are known to struggle with capturing behavior.

RDA utilities solely depend on the players' incomes, which are salient features in majority bargaining. It is expressed via linear utility functions $u_{i}=x_{i}+\alpha x_{j}$ of payoffs $\left(x_{i}, x_{j}\right)$ where the degree of altruism $\alpha$ depends on the relation of the payoff $x_{i}$ to the reference point. The main idea is very simple: the degree of altruism is low if one's payoff is below the reference point and it is high otherwise. For example, one may be egoistic if one's payoff falls short of one's reference point, and one may be efficiency concerned otherwise. Like other reference dependence theories (e.g. Köszegi and Rabin, 2007), Breitmoser and Tan (2013) assume that the ex ante expected payoff serves as a reference point. In this paper, we also consider the co-player's payoff as an alternative reference point. This extension serves two purposes. First, many reference dependence studies feature either type of reference point, ex ante expectation and co-player's payoff. We therefore describe the two motives with RDA and experimentally test their validity. Second, the assumptions that the co-player's payoff serves as a reference point and that efficiency concerns operate "above" the reference point directly capture the interplay of efficiency and equity concerns, as found for example by Engelmann and Strobel (2004) in distribution choices under random role assignment in three-player dictator games.

RDA is a prima facie plausible explanation of majority bargaining, because it models the tradeoffs between efficiency and equity found in majority bargaining. In majority bargaining, inequality can arise through the acceptance of inequitable proposals, and inefficiencies can arise from delay (Compte and Jehiel, 2010). The efficiency-equity tradeoff is an important topic in public policy (Okun, 1975; $\mathrm{Ng}, 2000$ ). On the one hand, purely efficiency concerned proposers are indifferent with respect to the resulting allocation but seek mainly to avoid delay or breakdown. Hence, they make generous proposals, which we observe in experiments. However, experiments also show that proposers do not make inequitable proposals to their own disadvantage. This suggests the existence of equity concerns. On the other hand, inequity aversion cannot serve as the sole explanation of behavior. This is because purely inequity averse responders mainly fear the possibility that (upon rejection) they might get nothing, implying that they are willing to accept highly inequitable allocations as long as they are not left out. Instead, responders with both efficiency and equity concerns still fear the possibility of being left out, but they see the possibility of being in future winning coalitions much more positively, being efficiency 
concerned rather than feeling guilty in such coalitions. This raises their continuation utilities, and paradoxically again, such "conditionally efficiency" concerned responders are more likely to reject inequitable proposals than purely inequity concerned ones, implying that the proposer has to make equitable proposals.

The experimental outcomes we observe are indeed equitable. They are compatible with RDA, but incompatible with self-interest and other forms of social preferences. Based on our analysis, subjects behave egoistically below their reference points while they are, indeed, efficiency concerned above the reference point. That is, subjects are concerned with increasing their own payoff as long as the individual objective is not met, and are instead concerned with increasing efficiency when the individual expectation is met. Proposers make generous proposals whilst satisfying their reference point. Voters accept proposals that disadvantage fellow voters in order to meet their reference points, or they reject proposals that do not meet their reference point in hope of being proposer in the next round. This yields a plausible description of behavior in parliaments and committees.

Depending on the reference point, RDA predicts equal splits either within the winning coalition or within the grand coalition. This prediction explains our experimental observations very well. In a structural analysis that analyzes social preferences in conjunction with bounded rationality (QRE, McKelvey and Palfrey, 1995), we find that the preference parameters are approximately as hypothesized. In a book chapter discussing future research for QRE, Goeree et al. (2016) suggested applying QRE with the incorporation of social preference parameters to explaining the unanimous experimental observation of under-realized bargaining power in the Baron-Ferejohn game (p. 286). Our paper shows that this is indeed true. In addition, we confirm the underlying assumption of stationary strategies (Baron and Kalai, 1993; Eraslan, 2002).

Finally, we show that RDA similarly helps explain behavior in a number of related distribution and bargaining games. Specifically, we re-analyze the collection of mini dictator, ultimatum and trust games in Charness and Rabin (2002), and the collections of three-player dictator games in Engelmann and Strobel (2004) and Bolton and Ockenfels (2006). We compare the accuracy of RDA's predictions with those of the leading existing models, inequity aversion (Fehr and Schmidt, 1999) and charitable reciprocity (Charness and Rabin, 2002). We find that RDA is substantially better at explaining behavior in these classes of interactions than those models-out-of-sample. This reinforces the idea that the simple and intuitive notion of reference dependent altruism captures behavior in multiperson interactions and thus may indeed be a behavioral force in majority bargaining.

Section 2 presents the experimental design and predictions for various assumptions 
on preferences. Section 3 reports the results. Section 4 performs an out-of-sample analysis of these theories and compares their performance. Section 5 concludes.

\section{The experiment}

\subsection{Majority bargaining}

Our experiment implements the majority bargaining model of Baron and Ferejohn (1989) in two complementary ways: with indefinite horizon and with finite horizon. In each game, three players, $N=\{1,2,3\}$, have to divide $€ 24$ by majority decision. The smallest currency unit is .01 Euro. Using $C=24$, the set of feasible allocations is

$$
\mathbf{X}=\left\{\mathbf{x} \in \mathbb{R}^{|N|} \mid \mathbf{x} \geq 0, \sum_{i \in N} x_{i} \leq C, \forall i \in N: 100 x_{i} \in \mathbb{N}_{0}\right\}
$$

The first game that we test is the random-proposer game with a continuation probability of .95 after each round without agreement.

Game 1 (PB95). In each round, one player is recognized as proposer by a uniform draw from $N$. This player chooses $\mathbf{x} \in \mathbf{X}$, and the other players vote on $\mathbf{x}$. If one of them accepts, then the players' payoffs are $\mathbf{x}$. Otherwise, a new round begins with probability $\delta=0.95$ and the payoffs are $\mathbf{0}$ with probability $1-\delta=0.05$.

PB95 is outcome equivalent to the random-proposer game with infinite time horizon and discount factor $\delta=0.95$ if the players are risk neutral. This game has a plethora of subgame-perfect equilibria (Baron and Ferejohn, 1989), akin to folk theorems in repeated games, but analyses generally focus on equilibria in stationary strategies. Stationary strategies are independent of proposals and votes in previous rounds, and as such they are the least complex equilibrium strategies (Baron and Kalai, 1993) and imply uniqueness of ex ante equilibrium payoffs (Eraslan, 2002).

Ex ante, prior to proposer recognition, every player expects a payoff of $C / 3=8$ in stationary subgame perfect equilibrium (SSPE). Thus, payoff-maximizing voters accept any proposal that allocates them at least their "continuation payoff" $\delta 8=7.60$, which in turn are the costs of buying a vote. Payoff-maximizing proposers buy one vote and allocate the rest $16.40=24-7.60$ to themselves. Along the equilibrium path, proposals thus have the structure $(16.4,7.6,0)$ and are accepted immediately.

The second game implemented in our experiment is a random-proposer game iden- 
tical to $P B 95$ with the difference that it ends after one round, and if the first proposal is not accepted then players are paid their continuation payoffs from $P B 95$. Hence, "PBOO" is strategically equivalent to $P B 95$ for payoff-maximizing players, but as shown below, predictions differ if players have social preferences.

Game $2(P B O 0)$. A player is recognized as proposer by a uniform draw from $N$. This player chooses $\mathbf{x} \in \mathbf{X}$, and the other players vote on $\mathbf{x}$. If one of them accepts, then the players' payoffs are $\mathbf{x}$. Otherwise, the payoffs are $7.60=\delta C / 3$ per player.

If players maximize expected payoffs, the set of SPEs of $P B O 0$ corresponds with the set of SSPEs of $P B 95$ in the sense that equal proposal and voting decisions are made. The ex post payoff profile has the structure $(16.4,7.6,0)$ in both games. PBOO relates most closely to the three-player majority games by Diermeier and Gailmard (2006). They experimentally analyze a one-round majority game with disagreement payoffs that were asymmetric and either very low or very high. In particular, their disagreement payoffs are of different magnitude than the continuation payoffs of $P B 95$, whereas we equate these payoffs. Their results complement ours in that they also find that inequity aversion does not fit behavior. In relation to standard three-player ultimatum games, $P B O O$ differs in that the disagreement payoffs are positive and that acceptance of either player implements the proposal for both players.

\subsection{Social preferences}

We consider the following models of social preferences: FS inequity aversion, CR reciprocity, CES altruism, and reference dependent altruism (RDA).

$$
\begin{aligned}
U_{i}^{F S}(\mathbf{x}) & =x_{i}-\sum_{j \neq i} \alpha\left(x_{j}-x_{i}\right) \cdot I_{x_{i}<x_{j}}+\sum_{j \neq i} \beta\left(x_{j}-x_{i}\right) \cdot I_{x_{i} \geq x_{j}} \\
U_{i}^{C R}(\mathbf{x}) & =x_{i}-\sum_{j \neq i}\left(\alpha+\theta q_{j}\right)\left(x_{j}-x_{i}\right) \cdot I_{x_{i}<x_{j}}+\sum_{j \neq i}\left(\beta-\theta q_{j}\right)\left(x_{j}-x_{i}\right) \cdot I_{x_{i} \geq x_{j}} \\
U_{i}^{C E S}(\mathbf{x}) & =\left((1-\alpha) \cdot\left(1+x_{i}\right)^{\beta}+\frac{\alpha}{n} \sum_{j \neq i}\left(1+x_{j}\right)^{\beta}\right) / \beta \\
U_{i}^{R D A}(\mathbf{x}) & =x_{i}+\sum_{j \neq i} \alpha x_{j} \cdot I_{x_{i}<x^{*}}+\sum_{j \neq i} \beta x_{j} \cdot I_{x_{i} \geq x^{*}}
\end{aligned}
$$

FS inequity aversion captures behavior in games with fixed roles, e.g. ultimatum and trust games (Fehr and Schmidt, 1999, 2010). Generally, it is assumed that envy ( $\alpha$ ) out- 
weighs guilt $(\beta)$ and that guilt is bounded, i.e. $0 \leq \beta<\alpha$ and $\beta<1 /(n-1) .{ }^{1}$ Charness and Rabin (2002) extend FS inequity aversion by introducing a reciprocal component with weight $\theta$. This component is switched on $\left(q_{j}=1\right)$ if $j$ previously "misbehaved" by making a welfare-reducing decision, else $q_{j}=0$. CR reciprocity reduces to FS inequity aversion for $\theta=0$. If $\theta>0, \mathrm{CR}$-players tend to punish welfare-diminishing behavior of their opponents, as their altruism weights decrease after such "misbehavior". CES utility functions are used frequently in analyses of dictator and public goods games (Andreoni and Miller, 2002; Goeree et al., 2002; Cappelen et al., 2007). The functional form in Eq. (4) follows Cox et al. (2007) and is adopted for its numerical stability. Here, $\alpha$ measures the degree of altruism, and $1 /(1-\beta)$ is the elasticity of substitution.

RDA describes how altruism is high (low) if the payoff is at or above (below) the reference point $x^{*}$. Following previous work, we distinguish two kinds of reference points. RDA with the absolute reference point defined by the ex ante expected payoff (following e.g. Köszegi and Rabin, 2007) is abbreviated ARDA, and RDA with the relative reference point defined by the opponent's payoff (following e.g. Fehr and Schmidt, 1999) is abbreviated RRDA. Intuitively, $\alpha<\beta<1$ holds, i.e. players reaching their reference point are "content" and thus more willing to share. ${ }^{2}$ Critically, $\alpha<\beta$ implies that utilities exhibit a jump discontinuity at the reference point, which models that players substantially enjoy reaching their reference points. This mimics equity concerns in the case of RRDA. Further, it implies that RDA players are willing to take risks to reach their reference points, i.e. they are more likely to reject sub-par proposals.

Predictions for $P B 95$ and $P B 00$ diverge in opposite directions if players have social preferences other than RDA. Figure 1 illustrates by plotting the ranges of equilibrium proposals compatible with the four families of social preferences. This shows how the joint analysis of $P B 95$ and $P B O 0$ disentangles these theories. To understand the divergence of predictions, let us first consider FS inequity aversion. Utilities are denoted as $U(x, y, z)$, where $x$ is the payoff of the player in question, and $y, z$ are the interchangeable payoffs of his opponents. If guilt is limited as usual, $\beta<1 / 2=1 /(n-1)$, all proposers pay the value $y$ that is necessary to buy one vote and keep the rest to themselves. As a result, equilibrium proposals have the structure $(24-y, y, 0)$, where $y$ is the transfer necessary to buy a vote. In equilibrium, the utility of the recipient of this transfer equates with his continuation

\footnotetext{
${ }^{1}$ Blanco et al. (2011) find that this assumption fits well on average, but in certain dictator games some subjects appear to have $\beta>1$. These subjects go beyond equalizing payoffs, in favor of the recipient, which is not observed in our experiment on majority bargaining with 1:1 transfers.

${ }^{2}$ For ARDA-players, $\alpha<\beta$ implies that they are less altruistic toward all their opponents before their payoffs meet their ex ante expectations. In contrast, $\alpha<\beta$ implies for RRDA-players that they are less altruistic toward a specific opponent once their payoff falls below the payoff of that particular opponent.
} 
Figure 1: The ranges of proposals that are compatible with the preference theories (Note that CR reciprocity is equivalent to FS inequity aversion here)

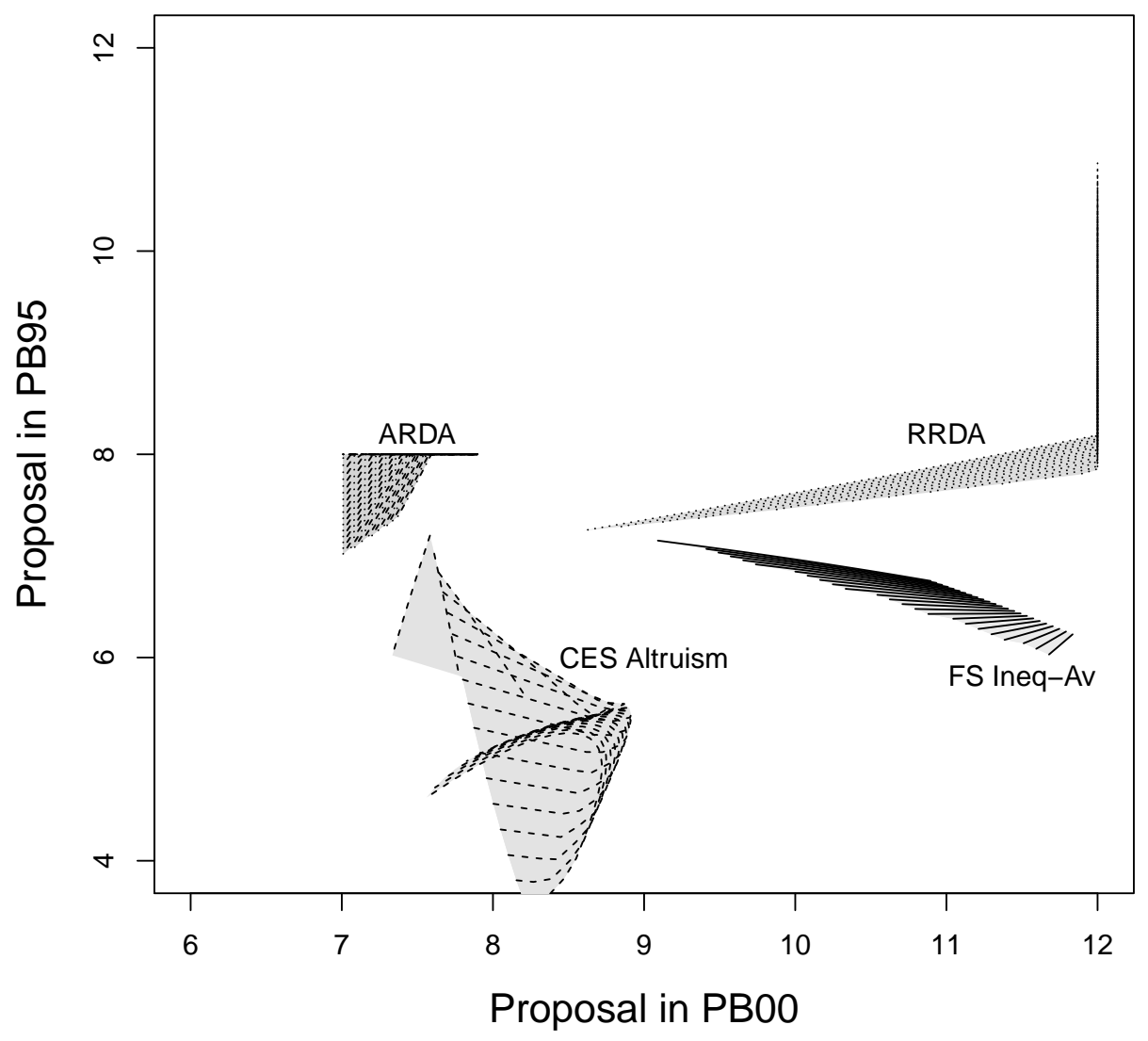

Note: Displayed are the predicted proposals to the player whose vote is bought. We focus on $\alpha, \beta \geq 0.1$, as all models degenerate to egoism for $\alpha, \beta \approx 0$. Specifically, CES altruism Eq. (4) for $\alpha \in[.1, .5]$ and $\beta \in[.1, .9]$, FS inequity aversion Eq. (2) or CR reciprocity Eq. (3) for $\alpha \in[.1,1]$ and $\beta \in[.1, .33]$, absolute reference dependence Eq. (5) for $\alpha \in[-.33, .33]$ and $\beta \in[.16, .66]$, and relative reference dependence Eq. (5) for $\alpha \in[.1, .33]$ and $\beta \in[.44, .88]$. Note that proposal range compatible with ARDA degenerates to a point in stationary SPEs of PB95 for all $\beta-\alpha>1 / 4$.

utility, and assuming stationarity, and this yields the following equilibrium condition. ${ }^{3}$

PB95: $\quad U(y, C-y, 0)=\frac{\delta}{3}(U(C-y, y, 0)+U(y, C-y, 0)+U(0, C-y, y))+(1-\delta) U(0,0,0)$

In contrast, the equilibrium transfer in $P B O 0$ ensures that the player whose vote is bought

\footnotetext{
${ }^{3} \mathrm{~A}$ standard continuity argument implies that at least one voter accepts in case of indifference. Assume there is an equilibrium where both voters reject in case of indifference. Then the proposer must offer $y$ such that $U(y, C-y, 0)>\tilde{u}$, but there is no optimal $y$ in this case, hence no equilibrium. In turn, it is clear that there is an equilibrium where the voters accept in case of indifference, as unilateral deviations are not profitable when one is indifferent.
} 
is indifferent between $(y, C-y, 0)$ and implementing the disagreement payoffs,

PBOO: $U(y, C-y, 0)=U(\delta C / 3, \delta C / 3, \delta C / 3)$.

These conditions have the same solution if players maximize payoffs, $U_{i}(\mathbf{x})=x_{i}$. If the utility is weakly concave (as in FS inequity aversion) or strictly concave (CES altruism), then the continuation utility in $P B 95$ is less than the disagreement utilities in $P B O 0$. This simply obtains as ex post payoffs are inequitable in $P B 95$ and equitable in $P B 00$, with the latter being the mean of the former. In conjunction with concave utilities, this yields said relation, ${ }^{4}$ and since continuation utilities of all players are lower, the costs of vote buying are smaller in $P B 95$ than in $P B 00$. Solving the above conditions for $y$ yields the following equilibrium transfers under FS inequity aversion.

$$
y_{95}=C \cdot \frac{3 \alpha+\delta(1-2 \beta-2 \alpha)}{3+6 \alpha-3 \beta-2 \delta \cdot(\alpha+\beta)} \quad y_{00}=C \cdot \frac{\delta / 3+\alpha}{1+2 \alpha-\beta} .
$$

This implies $y_{95}<7.60=\delta C / 3$ and $y_{00}>7.60=\delta C / 3$ under the standard assumptions $(0<\beta<\alpha$ with $\beta<1 / 2$ if $n=3)$. Inequity averse players make less equitable transfers than payoff maximizers in $P B 95$ and more equitable transfers than payoff maximizers in PBOO (Montero, 2007, discusses the former in detail). This holds similarly for all utility functions $U$ that are weakly concave in the payoff profile, such as CES altruism, but the predictions of FS inequity aversion and CES altruism differ quantitatively, as Figure 1 shows. Further, assuming proposers waste no part of the surplus, they do not "misbehave" as defined by Charness and Rabin (2002). Thus, negative reciprocity is irrelevant, rendering the theories of FS inequity aversion and CR reciprocity behaviorally equivalent in majority bargaining. That is, FS inequity aversion and CR reciprocity predict equivalent behavior along the path of play, and in agreement with CES altruism, they predict inequitable transfers in $P B 95$.

In contrast, RRDA and ARDA predict equitable transfers in both PB95 and PBO0. RDA induces a utility jump at the reference point which in turn breaks the weak concavity. Proposers have the bargaining power to make proposals that satisfy their reference points, in which case they enjoy a utility jump, and can thus behave generously at the same time. Conversely, voters reject proposals that do not meet their reference point, and would prefer

\footnotetext{
${ }^{4}$ To see this, consider a two-player game with (a) ex post payoffs $\left(x_{1}, x_{2}\right)$ and $\left(x_{2}, x_{1}\right)$ with 0.5 probability each and (b) alternatively $y=\left(x_{1}+x_{2}\right) / 2$ with certainty. For any concave utility function, expected utility in the former case is less than the (expected) utility in the latter case. The above simply extends this observation to three players.
} 
to gamble on the chance of being recognized as proposer in the next round. Thus, RDA players require larger compensation from proposals than egoistic players. On the one hand, under RRDA, the voters require a comparably large compensation as long as the proposer gets more than them. Solving the above equilibrium conditions for $y$ yields

$$
y_{95}=\frac{(\delta(1+2 \alpha)-3 \alpha) C}{(\alpha-\beta) \delta+3(1-\alpha)} \quad y_{00}=\frac{(\delta(1+2 \beta)-3 \alpha) C}{3(1-\alpha)},
$$

assuming $\beta<1$. Thus, both $y_{00}$ and $y_{95}$ are greater than $\delta C / 3$ under RRDA, for all $\beta>\alpha$. This prediction differs qualitatively from the predictions of the weakly concave utilities discussed above, and it is compatible with the equitable proposals observed by Fréchette et al. (2005a,b). Further, as the emotional bonus $\beta-\alpha$ of reaching the reference point increases, the vote buying costs $y$ increase further, up to $y=12$ in PBOO.

On the other hand, under ARDA, players accept any proposal that allocates them at least their ex ante expectation (for a very wide range of parameter constellations). If $\beta-\alpha$ is not too small, they reject any other proposal and the equilibrium proposal is $y=8$ in $P B 95$. The result is similar in $P B 00$, where the equilibrium proposal can be shown to satisfy 7.6 $<y<8$ for a wide range of parameters, e.g. for all $\delta<1$ and $\alpha<0$. Thus, ARDA predicts proposals close to $y=8$ in both games, as shown in Figure 1.

In light of the conditional efficiency concerns observed by Charness and Rabin (2002) and Engelmann and Strobel (2004), we hypothesize that RDA players are largely egoistic below their reference point $(\alpha \approx 0)$ and largely efficiency concerned above their reference point $(\beta \approx 1)$. In these extreme cases, ARDA players are indifferent between all $(24-$ $y, y, 0)$ with $y \in[8,16]$; their average proposals are therefore $(12+\varepsilon, 12-\varepsilon, 0)$ if $\beta$ is close to 1 . This predicts roughly equal splits within the winning coalition. RRDA players converge to $(8,8,8)$ in the limit, ${ }^{5}$ i.e. equal splits within the grand coalition.

\subsection{Experimental logistics}

The experiment was conducted in the experimental economics laboratory at the Europa Universität Viadrina, Frankfurt (Oder), Germany. The experiment was, apart from the experimental instructions and control questionnaire, fully computerized (using z-Tree, see Fischbacher, 2007). Subjects were students from various faculties of the university. An announcement for this experiment was sent to recipients on an email database of potential

\footnotetext{
${ }^{5}$ To be precise, in the limit, RRDA players are indifferent between all allocations giving them at least as much as each opponent. However, they maximize the probability of acceptance by donating equitably (pleasing both opponents under RRDA) if there is infinitesimal noise (e.g. logistic voting).
} 
subjects. Those who responded to the email were recruited accordingly.

We conducted a total of nine sessions: five sessions of $P B 95$ and four sessions of $P B 00$. The between-subject design prevents carryover effects across these two types of games. Each session had 12 subjects. A total of 108 subjects participated. Each subject was allowed to participate only once. Each session was partitioned into two sub-sessions, to each six subjects were randomly assigned. Subjects never interacted with those from other sub-sessions. We partitioned the sessions to increase the number of independent observations, and ran sub-sessions simultaneously to enhance the sense of anonymity.

The subjects' tasks and information conform precisely to the definitions of the two games provided above. Subjects were matched into groups of three and stayed in the same groups during each game. Each PB95 game progressed in "rounds", while each PBO0 game had one round. Subjects were randomly assigned their roles (proposer or voter) at the beginning of each round. During each round, voters were informed of the proposals made. At the end of each round, subjects were informed of the outcomes of that round. At the end of each game, subjects were informed of the outcomes of that game. This follows the way the games are theoretically defined.

In the experiment, each subject played 10 games. Repetition allows for experience and learning. To implement the one-shot context, we randomly rematched subjects after each game to eliminate reputational and reciprocal effects across games. This method was first proposed by Andreoni (1988), and has been adopted as standard practice in economics experiments since. By running sub-sessions simultaneously, we reduced the perceived probability of being rematched with the same co-players. With 12 subjects per session, the perceived probability of being rematched with a given co-player in the next round was $p=2 / 11$ and that of being rematched in the same group was $p<0.04$. Subjects could not attribute others' actions and outcomes from previous games to specific individuals as 1) groups were randomly rematched for each game, 2) subjects' identities were kept anonymous, and 3) roles were randomly reallocated. Direct reciprocity was thus impossible.

At the beginning of the experiment, subjects were randomly assigned computer terminals. They started by reading the experimental instructions, provided on printed sheets, followed by answering a short control questionnaire that allowed us to check their understanding. Neutral language was used throughout the experiment (e.g. "A-participant" and "B-participant" instead of "proposer" and "voter", and "stage" instead of "game"). The instructions used in PB95 sessions are provided as supplementary material. Subjects in doubt were verbally advised by the experimental assistants before being allowed to begin. Each computer terminal was partitioned, so that subjects were unable to communicate via 
audio or visual signals, or to look at other computer screens. Decisions were thus made in privacy. At the end of the experiment, subjects were informed of their payments, and asked to privately choose a codename and password. This was used to anonymously collect their payments from an independent third party not involved in running or planning the experiment in the week after the experiment. This procedure enhanced subject privacy. Each subject was given $\mathrm{a} € 4$ participation fee and the earnings from one randomly chosen game. The marginal incentives could therefore range from $€ 0$ to $€ 24$ per subject. The average payout was above $€ 11$ per subject for, on average, less than 1 hour per session. ${ }^{6}$

\section{Results}

\subsection{Behavioral patterns}

In this section, we analyze the qualitative compatibility of the experimental observations with the predictions of the different theories. Proposals are denoted as $\left(x_{p}, x_{h}, x_{l}\right)$, where $x_{p}$ is the proposer's payoff, $x_{h}:=\max \left\{x_{1}, x_{2}\right\}$ is the higher of the voters' payoffs, and $x_{l}=\min \left\{x_{1}, x_{2}\right\}$ is the lower of the voters' payoffs. Table 1 shows that the average payoffs of voters exceed the SSPE predictions for egoistic players, $x_{h}=7.6$ and $x_{l}=0$. The average payoffs are $\left(x_{p}, x_{h}, x_{l}\right)=(10.62,8.60,4.15)$ for $P B 95$ and $(10.23,8.84,4.19)$ for PBOO. Mann-Whitney $U$ tests taking the average of each sub-session as an independent observation show that the proposal components $x_{p}, x_{h}$, and $x_{l}$ are not significantly different between $P B 95$ and $P B O 0$ ( $p=0.633$ for $x_{p}, p=0.696$ for $x_{h}, p=0.965$ for $x_{l}$ ). This holds robustly in both the first and the second half of the experiment. In this respect, the results are compatible with RRDA and ARDA, which predict that outcomes are equitable and similarly so in $P B 95$ and $P B 00$. In turn, they are not compatible with CES altruism, and FS inequity aversion or CR reciprocity, which predict $x_{h}<7.6$ in $P B 95$ and $x_{h}>7.6$ in PBOO. ${ }^{7}$

Figure 2 plots the distributions of proposals and voting behavior in $P B 95$ and $P B O 0$. Figure 2 a plots the distributions of proposals made to each of the two voters. These distributions are plotted in relation to the empirical continuation payoffs, which are 7.36 in $P B 95$ and 7.60 in $P B 00$. The plots include the proposals that were not accepted, which are

\footnotetext{
${ }^{6}$ The monetary incentives provided in our experiment are substantial by local standards. Our mean payment of above $€ 11$ per hour is, for example, $50 \%$ more than the mean wage of a research assistant.

${ }^{7}$ Regression analyses of player-specific payoffs controlling for game (for both treatments) and round (for PB95) confirm the above, and also show that stationarity and truncation consistency are not violated. The details are provided as supplementary material.
} 
Table 1: Means (and standard errors) of the proposals for first and second halves of the experiment

\begin{tabular}{ccccccc}
\hline \hline & \multicolumn{2}{c}{ Proposer payoff $x_{p}$} & \multicolumn{2}{c}{ Higher payoff $x_{h}$} & \multicolumn{2}{c}{ Lower payoff $x_{l}$} \\
& $\mathrm{G} \mathrm{1-5}$ & $\mathrm{G} \mathrm{6-10}$ & $\mathrm{G} \mathrm{1-5}$ & $\mathrm{G} \mathrm{6-10}$ & $\mathrm{G} \mathrm{1-5}$ & $\mathrm{G} \mathrm{6-10}$ \\
\hline PB95 & 10.266 & 10.992 & 8.365 & 8.911 & 4.676 & 3.548 \\
& $(0.5465)$ & $(0.6411)$ & $(0.3369)$ & $(0.3976)$ & $(0.5542)$ & $(0.5554)$ \\
PB00 & 9.57 & 10.899 & 8.273 & 9.403 & 4.887 & 3.484 \\
& $(0.7255)$ & $(0.531)$ & $(0.5503)$ & $(0.3458)$ & $(0.6133)$ & $(0.6421)$ \\
\hline \hline
\end{tabular}

Note: The standard errors are computed using the sub-session means as independent observations. The values for "G 1-5" refer to the first five games per session, those for "G 6-10" refer to the last five games per session.

Figure 2: The distribution of proposals and the voting decisions

(a) Proposals in relation to the (empirical) continuation payoffs in $P B 00$ and $P B 95$
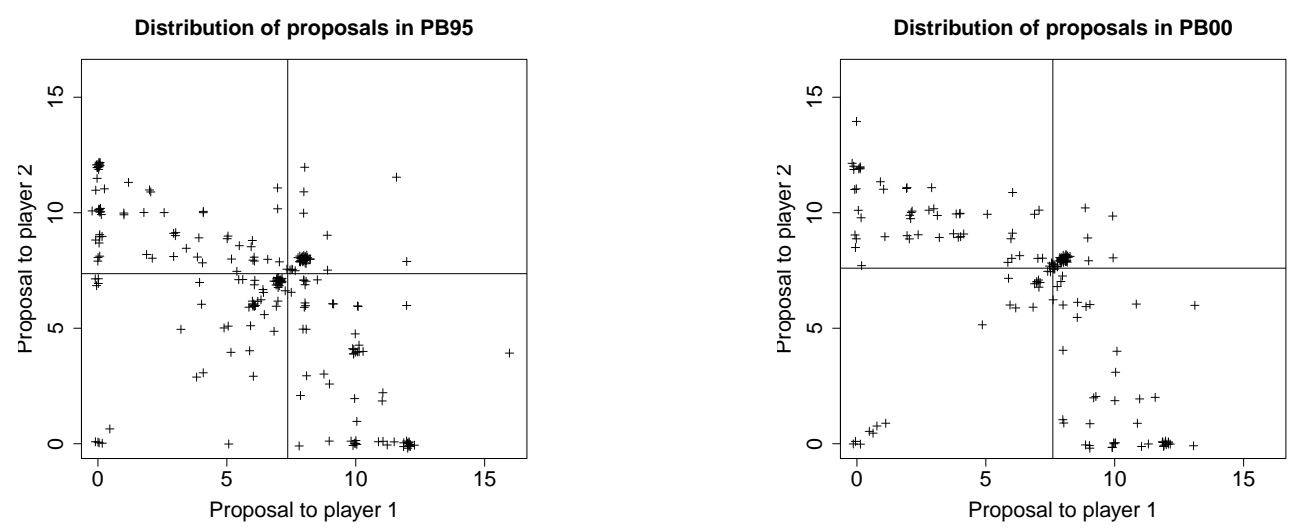

Note: The empirical estimate of expected payoff in $P B O 0$ is 7.88 , and the estimated discounted payoff (continuation payoff) in $P B 95$ is 7.36 . The points are slightly perturbed to visualize their clustering.

(b) Voting functions (relative acceptance frequencies)
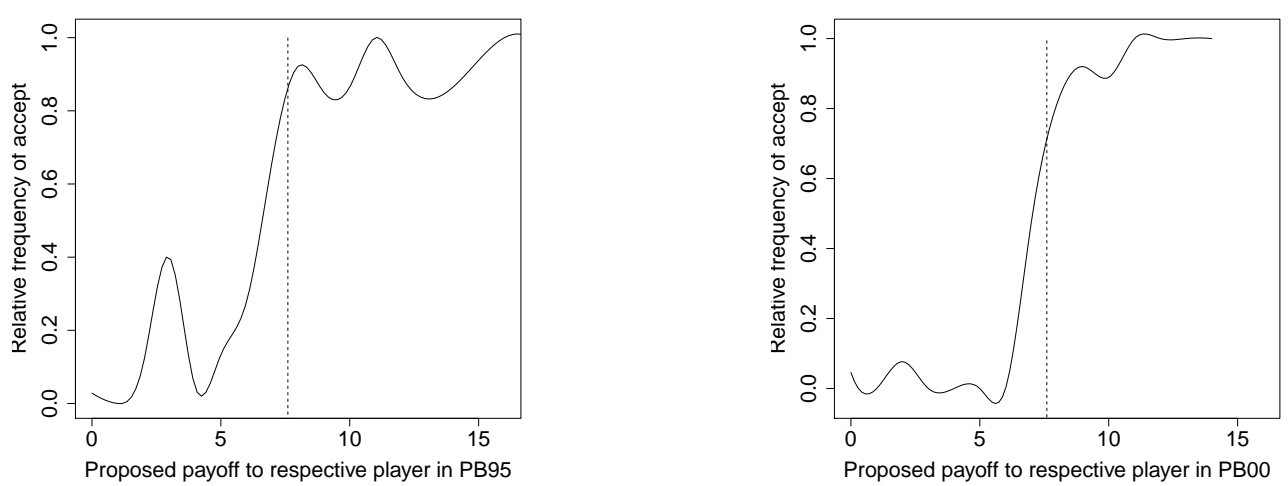
located mostly in the lower-left quadrant. The vast majority of proposals is in the other three quadrants, where at least one voter's continuation payoff is met. These proposals had mostly been accepted; Figure $2 b$ shows that offering at least one opponent a payoff of 8 ensures acceptance with high probability. We can see in Figure 2a that the proposals in both treatments are located roughly along a concave frontier stretching from around $\left(x_{h}, x_{l}\right)=(10,0)$ through $(8,8)$ to $(0,10)$. The distributions have three mass points. In $P B 95$, around 30 proposals are at $(12,0)$ or $(0,12)$, and another 30 proposals are at $(8,8)$. In $P B 00$, the mass points at $(12,0)$ and $(0,12)$ are less populated. Figure 2a shows that further observations are clustered near these mass points: there is a cluster of proposals allocating 9-12 to one opponent and zero or negligible amounts to the other one and a second area to the southwest of $(8,8)$.

These cluster areas fit the predictions of RDA. On the one hand, ARDA predicts proposals of the form $(12+\varepsilon, 12-\varepsilon, 0)$ if $\beta$ is close 1 . ARDA is thus qualitatively compatible with the observations around $\left(x_{h}, x_{l}\right)=(10,0)$ in Figure $2 \mathrm{a}$, if we allow $\beta$ to be slightly below 1 . RRDA is compatible with the observations around $\left(x_{h}, x_{l}\right)=(8,8)$, suggesting that their $\beta$ is indeed close to 1 . Further, almost all observations near $(8,8)$ in Figure $2 \mathrm{a}$ are to its southwest, i.e. the proposer gets at least as much as the voters in all cases. This strong relational effect uniquely fits RRDA, as it is the only model predicting that proposer utility drops substantially if they get less than the voters. In either case, the voters theoretically accept proposals if $y \approx 8$, which is also empirically satisfied (Figure $2 b$ ). As discussed above, and by Montero (2007), these observations are incompatible with weakly concave utility functions.

\subsection{Modeling motives}

In this section, we econometrically verify the qualitative observations made above. We estimate the utility functions using a structural model of behavior, quantal response equilibrium (QRE, McKelvey and Palfrey, 1995), and evaluate their adequacy in relation to the data. QRE relaxes the assumption of "best responses" toward "better responses", i.e. that players do not solely choose best responses. Still, the more profitable an option is, the higher is its choice probability. Specifically, we model $P B 00$-choices as agent logit equilibria (McKelvey and Palfrey, 1998) and PB95-choices as stationary logit equilibria (Breitmoser et al., 2010), which we jointly abbreviate as SLE. Due to the large strategy sets, ${ }^{8}$

\footnotetext{
${ }^{8}$ Our analysis uses a smallest currency unit of $€ 0.2$, and given the cake sizes of $€ 24$, this implies that the number of possible proposals is on the order of $10^{6}$ in each round.
} 
we will also consider a generalization called stationary nested logit equilibrium (SNLE). Nested logit (McFadden, 1978, 1984) allows for the possibility that subjects choose proposals in multiple decision steps. The clustering displayed in Figure 2a suggests that this is a possibility, and in particular it suggests that subjects first determine how many opponents and whom they pay their continuation payoffs (to buy the vote) before they choose the actual allocation. In order to be on the save side, we control for this possibility, but the qualitative results do not depend on the adopted choice model. The technical details of nested logit in stationary equilibria are provided in the supplementary material.

The clustered observations discussed in the previous section suggest a subject pool with two discrete components. We model subject heterogeneity of this discrete nature using finite mixture models (McLachlan and Peel, 2000). This allows us to simultaneously estimate number, weights, and utility as well as choice parameters of subject types. To define the likelihood function, let $K$ denote the set of components in the population with weights $v_{k}$ and behavioral parameter tuple $\mathbf{p}^{k}$ for all $k \in K$. Thus with $\mathbf{P}=\left(\mathbf{p}^{k}\right)_{k \in K}$ as the behavioral parameter profile, and with $\mathbf{O}=\left(o_{s, t}\right)$ as the set of observations for all subjects $s \in S$ and periods $t \in T$, the log-likelihood is

$$
L L(\mathbf{P} \mid \mathbf{O})=\sum_{s \in S} \ln \sum_{k \in K} v_{k} L(s, k) \quad \text { with } \quad L(s, k)=\prod_{t \in T} \sigma\left(o_{s, t} \mid \mathbf{p}^{k}\right),
$$

using $\sigma\left(o_{s, t} \mid \mathbf{p}^{k}\right)$ as the probability of action $o_{s, t}$ according to the QRE defined by the parameter profile $\mathbf{p}^{k}$. The log-likelihood is maximized jointly over all parameters to obtain consistent and efficient estimates (see e.g. Amemiya, 1978, and Arcidiacono and Jones, 2003, for further discussion), and to allow us to extract standard errors from the information matrix. ${ }^{9}$ We evaluate the significance of differences between models using standard likelihood-ratio tests (Vuong, 1989), nested or non-nested as required, applied to the standard information criterion ICL-BIC for finite mixture models (Biernacki et al., 1999, 2000). ${ }^{10}$

\footnotetext{
${ }^{9}$ We use the derivative-free NEWUOA algorithm (Powell, 2008) for the initial approach toward the maximum (NEWUOA is a comparably efficient and robust algorithm, see Auger et al., 2009, and Moré and Wild, 2009), and subsequently, we use a Newton-Raphson algorithm to ensure local convergence. This procedure has been repeated using a variety of starting values. The complete list of parameter estimates is provided as supplementary material.

${ }^{10} I C L-B I C$ is comparable to the well-known Bayes information criterion (BIC, Schwarz, 1978) but additionally penalizes mixture models with superfluous components. This resolves the issue that BIC overestimates the number of components ("subject types") of finite mixture models. BIC is defined as $B I C=-L L+d / 2 \cdot \log (O)$ with number of parameters $d$ and number of observations $O$ (Schwarz, 1978). The integrated classification likelihood-BIC to be used for mixture models is defined as $I C L-B I C=$ $-L L+d / 2 \cdot \ln O+\operatorname{En}(\hat{\tau})$ using the entropy $\operatorname{En}(\hat{\tau})=-\sum_{s \in S} \sum_{k \in K} \hat{\tau}_{s k} \ln \hat{\tau}_{s k}$ of posterior component membership, where $\hat{\tau}_{s k}=\frac{v_{k} L(s, k)}{\sum_{k^{\prime} \in K} v_{k^{\prime}} L\left(s, k^{\prime}\right)}$. For discussion, see Biernacki et al. $(1999,2000)$.
} 
Table 2: Robustness checks of the identified motives

(a) Goodness-of-fit (ICL-BIC) of logit (SLE) vs. nested logit (SNLE)

\begin{tabular}{|c|c|c|c|c|c|c|c|}
\hline \multirow[b]{2}{*}{ Utility function } & \multicolumn{7}{|c|}{ Number of components ("subject types") } \\
\hline & SLE $\times 1$ & & SNLE $\times 1$ & & SNLE $\times 2$ & & SNLE $\times 3$ \\
\hline CES Altr & 4513.13 & $\lll$ & 3992.96 & $\lll$ & 3890.92 & $\lll$ & 3702.54 \\
\hline IneqAv & 4570.67 & $\lll$ & 3835.85 & $\lll$ & 3700.56 & $\lll$ & 3666.14 \\
\hline RRDA & 4131.97 & $\lll$ & 3668.32 & $\lll$ & 3469.22 & $=$ & 3486.81 \\
\hline ARDA & 4344.01 & $\lll$ & 3621.68 & $\lll$ & 3488.86 & $=$ & 3512.42 \\
\hline
\end{tabular}

Note: Goodness-of-fit if we allow for up to three types of subjects with either CES altruism Eq. (4), inequity aversion Eq. (2), or reference dependent altruism Eq. (5). We distinguish stationary logit and nested logit equilibria, SLE and SNLE, respectively, where the multiplier denotes the number of subject types being distinguished. The parameter estimates are supplementary material.

(b) Goodness-of-fit (ICL-BIC) of mixture models with two differing motives

\begin{tabular}{lccccccc}
\hline \hline & \multicolumn{7}{c}{ Second component } \\
\cline { 2 - 8 } First component & CES Altr & & IneqAv & RRDA & ARDA \\
\hline CES Altr & 3890.93 & $\ll$ & 3730.59 & $\ll$ & 3591.86 & $=$ & 3607.17 \\
IneqAv & 3730.81 & $=$ & 3701.2 & $\lll$ & 3534.5 & $=$ & 3524.85 \\
RRDA & 3591.48 & $=$ & 3534.87 & $\ll$ & 3469.22 & $<$ & 3415.11 \\
ARDA & 3607.18 & $<$ & 3524.8 & $\ll$ & 3415.11 & $>$ & 3488.85 \\
\hline \hline
\end{tabular}

(c) Goodness-of-fit $(I C L-B I C)$ of mixture models with three different components

\begin{tabular}{lccccccc}
\hline \hline & \multicolumn{7}{c}{ Third component } \\
\cline { 2 - 8 } First two components & CES Altr & & IneqAv & RRDA & & ARDA \\
\hline CES + IneqAv & 3744.59 & $=$ & 3750.76 & $\lll$ & 3513.81 & $=$ & 3533.84 \\
CES + RRDA & 3500.23 & $=$ & 3513.52 & $=$ & 3531.01 & $\lll$ & 3423.75 \\
Ineq + ARDA & 3533.81 & $=$ & 3517.12 & $\lll 3404.32$ & $\ggg$ & 3537 \\
RRDA + ARDA & 3423.74 & $=$ & 3405.07 & $=$ & 3422.73 & $=$ & 3437.96 \\
\hline \hline
\end{tabular}

Note: Tables (b)-(d) display the ICL-BIC criteria of model fit, Fn. (10), and the results of nested/nonnested Vuong tests on ICL-BIC for adjacent models (following the suggestion of (Vuong, 1989, Eq. 5.9), we perform likelihood ratio tests including the BIC correction term and the model entropy $\operatorname{En}(\hat{\tau})$ ). The signs “<, «, «" indicate significant improvements at $\alpha=.1, .01, .001$, respectively (note that "less is better" if goodness-of-fit is measured by information criteria such as $I C L-B I C$ ).

Tables $2 \mathrm{a}-2 \mathrm{c}$ summarize the results of the structural analysis. The underlying parameter estimates are provided as supplementary material. First, we verify whether choice is captured by a one-step logit process or by the two-step nested logit process described above. The results are given in columns "SLE $\times 1$ " and "SNLE $\times 1$ " of Table $2 \mathrm{a}$, respectively, and rather strongly show that for all utility functions, model adequacy improves by about 500 points on the log-likelihood scale if we allow for the two-step "hierarchical" choice process where subjects first pick whom to pay the continuation payoff. That is, choice violates IIA (independence of irrelevant alternatives) highly significantly, but notably, the best-fitting utility functions are ARDA and RRDA in either case. Table 2a also informs on the necessity to distinguish multiple components (or, subject types) as- 
suming all components are either CES, FS, ARDA, or RRDA. Regardless of the utility function assumed, at least two components are to be distinguished in the population (compare columns "SNLE $\times 1$ " and "SNLE $\times 2$ "), but again, ARDA and RRDA are most adequate in either case.

Secondly, given that at least two components are to be distinguished, we determine the most adequate two-component model by evaluating all possible combinations. Table $2 \mathrm{~b}$ reports the results. It shows that regardless how the first component is modeled, comparing columns "CES Altr" and "IneqAv" across all rows, a second component with FS inequity aversion fits better than CES. Next, RRDA fits significantly better than FS inequity aversion across rows, comparing columns "IneqAv" and "RRDA", and the differences amount to more than 100 points on the log-likelihood scale (or, $p<0.01$ ) in all cases. Thus, at least one component is estimated to be RRDA or ARDA. Using either of ARDA and RRDA as first component, we find that one complements the other best, and the differences to the alternative combinations are highly substantial in terms of $I C L$ $B I C$ - again at least 100 points on the log-likelihood scale. This strongly confirms our qualitative observations made above, that behavior aligns with ARDA and RRDA but not with FS inequity aversion and CES altruism.

Thirdly, Table $2 \mathrm{c}$ determines the structure of a possible third component (however small), i.e. the composition of a third subject type potentially differing from ARDA and RRDA. To provide the general picture, we estimate 16 three-component models. All mixtures not including both RRDA and ARDA components have ICL-BIC values above 3500 points, and thus must be considered inadequate again. The best-fitting three-component model, and indeed the only model that improves upon the pure RRDA + ARDA mixture in terms of $I C L-B I C$, identifies a third component of subjects with FS inequity aversion. The parameter estimates (Table 3) show that the previously identified RRDA component is split up into two components, into one of RRDA and one of FS inequity aversion. The share of FS subjects is significant in relation to its standard error and in Vuong likelihoodratio tests $(p<.01)$, but overall it is small $(7.2 \%){ }^{11}$

Table 3 provides the detailed parameter estimates and standard errors of the most adequate models. If we distinguish the two components identified based on Table $2 \mathrm{~b}, 55 \%$ of the subjects have RRDA preferences and $45 \%$ of them have ARDA preferences. The rather balanced distribution of RRDA and ARDA types corresponds with the previous observations that the two cluster areas contain similar numbers of observations. As indicated, the RRDA component can be further split down into a sub-component with RRDA

\footnotetext{
${ }^{11}$ Since the third component is already very small, estimation of a possible fourth component is skipped.
} 
Table 3: The estimation results

\begin{tabular}{lcccccccr}
\hline \hline Component & Weight & $\lambda_{p}$ & $\rho_{1}$ & $\rho_{2}$ & $\lambda_{v}$ & $\alpha$ & $\beta$ & $I C L / L L / R^{2}$ \\
\hline RRDA & 0.552 & 5.542 & 0.145 & 0.101 & 0.001 & 0.27 & 0.998 & \\
& $(-)$ & $(0.093)$ & $(0.004)$ & $(0.001)$ & $(0.002)$ & $(0.002)$ & $(0.007)$ & 3415.11 \\
ARDA & 0.448 & 3.332 & 0.119 & 0.088 & 0.317 & 0.334 & 0.795 & -3346.74 \\
& $(0.054)$ & $(0.042)$ & $(0)$ & $(0)$ & $(0.002)$ & $(0)$ & $(0.006)$ & 0.8914 \\
\hline RRDA & 0.481 & 5.653 & 0.127 & 0.094 & 0 & 0.277 & 0.996 & \\
& $(-)$ & $(0.027)$ & $(0.001)$ & $(0)$ & $(0)$ & $(0.002)$ & $(0)$ & \\
ARDA & 0.447 & 4.604 & 0.148 & 0.024 & 0.328 & 0.36 & 0.732 & 3405.07 \\
& $(0.055)$ & $(0.029)$ & $(0)$ & $(0.001)$ & $(0.002)$ & $(0)$ & $(0.003)$ & -3306.89 \\
IneqAv & 0.072 & 0.894 & 0.157 & 0.011 & 0.498 & 0.004 & 0.056 & 0.003 \\
& $(0.023)$ & $(0.011)$ & $(0.006)$ & $(0.003)$ & $(0.01)$ & $(0)$ & $(0.001)$ & 0.8958 \\
\hline \hline
\end{tabular}

Note: $(\alpha, \beta)$ are the parameters of the four utility functions, the remaining parameters are the choice parameters discussed in the supplementary material. The standard errors are provided in parentheses. The Cox-Snell Pseudo- $R^{2}$ is $R^{2}=1-\left(L\left(M_{\text {Baseline }}\right) / L\left(M_{\text {Full }}\right)\right)^{2 / O}$, with the "baseline model" being the benchmark that players randomize uniformly in all cases and $O$ being the number of observations.

preferences (48.1\%) and a sub-component with FS inequity aversion containing $7.2 \%$ of the subjects, but overall the share of FS inequity averse subjects is small. The estimated RRDA and ARDA parameters also correspond with the observations made in the previous section. The RRDA component has $\beta \approx 1$, which means that RRDA players are approximately welfare-concerned as long as they get at least as much as their opponents. This explains the cluster around $\left(x_{h}, x_{l}\right)=(8,8)$. The ARDA players have a large difference $\beta-\alpha$ and $\beta$ slightly below 1 , which explains the cluster around $\left(x_{h}, x_{l}\right)=(10,0)$.

\section{Predicting behavior in other games}

In this section, we evaluate the adequacy of RDA in relation to existing theories in outof-sample tests. We use data sets from seminal papers that relate closely to multi-player bargaining: the "simple tests" of Charness and Rabin (2002, CR02), which comprise mini dictator, ultimatum and trust games, the three-player dictator games analyzed by Engelmann and Strobel (2004, ES04) to illustrate the limits of inequity aversion as a general behavioral principle, and the three-player voting games analyzed by Bolton and Ockenfels (2006, BO06) in response to illustrate the limits of efficiency concerns. Clearly, any such test may only be indicative of RDA's general adequacy, although out-of-sample, but the above experiments have been designed to constitute tough tests of social preference theory, they insightfully highlight behaviors which current models struggle to explain, and all these experiments intuitively relate to multi-person bargaining problems. We therefore believe that these data sets constitute a test bed for RDA that is both challenging and 
informative, in particular considering that we strictly focus on out-of-sample tests.

The "simple distribution experiments" of Engelmann and Strobel (2004) consist of 11 three-person dictator games of three types: taxation games, envy games, and richpoor games. Taxation games were designed to compare the relevance of two theories of inequity aversion, namely ERC (Bolton and Ockenfels, 2000) and FS, while allowing for efficiency concerns and maximin preferences as modeled by Charness and Rabin (2002). Dictators choose between three allocations, one which is predicted by ERC and another by FS inequity aversion - in half of the games efficiency or maximin predicts the same as ERC and in the other half efficiency or maximin predicts the same as FS inequity aversion. "Envy games" further test the robustness of efficiency concerns by having dictators choose between inequitable but efficient allocations versus equitable but inefficient allocations, as do "rich-poor games" which additionally are neutral to maximin preferences.

In the three-person "voting games" of Bolton and Ockenfels (2006), allocations are determined by majority vote. There are two treatments: in the "straight mode", subjects knew their roles prior to voting, and in the "equal opportunity mode", one's actual role was unknown prior to voting and there was an equal chance of being allocated to each role (but votes are conditional on one's eventual allocation). Each player chooses between an equitable allocation $(13,13,13)$ versus an efficient allocation $(19,13,13)$ in Game I, $(27,1,17)$ in Game II, or $(27,9,9)$ in Game III. Relative to individual payoffs under the equitable allocation, the efficient allocation entails personal losses to none, majority, and minority of the players in Games I, II and III, respectively. Personal losses are larger in Game II than in Game III. These voting games analyze the tradeoff between equity and efficiency.

The "simple tests" of Charness and Rabin (2002) consist of 32 games: dictator games with two or three persons, and sequential-move response games with two or three persons. In response games, the first mover chooses whether to stop the game or to let the second mover choose. The second mover's payoffs are identical across choices in some games, and in others the second mover's sacrifice helps or hurts the first mover. ${ }^{12}$ In addition to tests of distributional and welfare concerns, response games allow for tests of reciprocity.

For each model, we determine predictions for each of the games and each of the roles. We refer to models allowing for heterogeneous subject pools as "heterogeneous models" and to models assuming homogeneous subject pools as "homogeneous models". Besides RDA, which is a heterogeneous model, we also report predictions based on ARDA or

\footnotetext{
${ }^{12}$ There were two games where the dictator's payoffs were unknown, and so are not analyzed here.
} 
RRDA separately of each other, which thus are homogeneous models. Throughout, we stick with the parameter estimates obtained above, see Table 3, and we use "RDA" to refer to the 55-45 mixture of RRDA and ARDA estimated above. ${ }^{13}$

In addition to predictions based on egoism ("Ego") and FS inequity aversion ("IneqAv"), we also test a heterogeneous model that considers both types of subjects. This follows Fehr and Schmidt (2010), who postulate that the subject pool consists of $60 \%$ egoists and $40 \%$ inequity averse types, which have $\alpha=2 /(n-1)$ and $\beta=0.6 /(n-1)$ in Eq. (2). We refer to this heterogeneous model as "FS-Full". In Charness and Rabin (2002, Table VI), one of the best-fitting models and its respective parameters estimated is their full reciprocity model ("CR-Full") with $\alpha=-.023, \beta=.424, \theta=-.111$ in Eq. (3). Its predictions are partially in-sample and pose a rather tough challenge for RDA's out-of-sample predictions. We also test predictions for CR02's reciprocal charity "RecChar" model, which nullifies envy by setting $\alpha=0$. CR02's estimates for RecChar are $\alpha=0, \beta=.425, \theta=-.089$, and its predictions are identical to CR-Full's in many games.

For all models and all games, we derive the unique predictions without noise and evaluate their adequacy using the quadratic scoring rule (Selten, 1998; Gneiting and Raferty, 2007). ${ }^{14}$ With $G$ as the set of games considered here, $A(g)$ as the action set in game $g \in G$, $n(a, g)$ as the number of subjects that chose $a$ in $g$, and $p(a, g)$ as the predicted probability of $a$ in $g$, the prediction scores are

$$
\text { Quadratic Score: } S_{Q}=-\sum_{g \in G} \sum_{a \in A(g)} \sum_{b \in A(g)} n(a, g) \cdot\left(I_{a=b}-p(b, g)\right)^{2} .
$$

Table 4 contains the overall scores, the scores for subsets of games, and in parentheses bootstrapped $p$-values of tests of differences to RDA (if $p<.1$, then the respective model fits significantly worse than RDA). The appendix contains the predictions of all models for all games. The main results are clear-cut and systematic across data sets. First, the heterogeneous models (RDA and FS-Full) fit better than all homogeneous models, but only RDA does so significantly. Second, RDA also fits better than the heterogeneous

\footnotetext{
${ }^{13}$ The predictions are invariant to the set of parameter estimates chosen from Table 3, which are estimated either with or without an additional component of inequity aversion. Reference points for ARDA are, consistent with the definition given after Eq. (5) and with the random role allocation feature of both experimental designs, the ex ante expectations prior to random role allocation, i.e. the equilibrium payoff of payoff-maximizing players averaged across roles.

${ }^{14}$ We evaluate the predictions without noise, as noise parameters such as those estimated above or by Charness and Rabin are not transferable across experiments. In case a model's prediction is indeterminate, we refine it in the sense of the respective theories. The Ego prediction is refined toward inequity aversion in cases of indeterminacy.
} 
Table 4: Out-of-sample fit of social preference models models (negative Quadratic scores, i.e. more is better), with $p$-values of significance in relation to RDA

\begin{tabular}{|c|c|c|c|c|c|c|c|c|c|}
\hline & \multicolumn{9}{|c|}{ Utility models } \\
\hline & Ego & ARDA & RRDA & RecChar & CR-Full & IneqAv & RDA & FS-Full & RDA-Ego \\
\hline Dictator Games ES04 & $\begin{array}{c}-440.02 \\
(0)\end{array}$ & -317.68 & -321.76 & $\begin{array}{c}-361.78 \\
(0.041)\end{array}$ & $\begin{array}{c}-361.78 \\
(0.041)\end{array}$ & -488.02 & $\underset{(-)}{-286.3}$ & $\begin{array}{c}-444.84 \\
(0)\end{array}$ & $\begin{array}{c}-306.36 \\
(0.353)\end{array}$ \\
\hline Voting Games BO06 & $\begin{array}{c}-192.48 \\
(0.072)\end{array}$ & $\begin{array}{c}-195.36 \\
(0.079)\end{array}$ & $\begin{array}{l}-228 \\
(0.009)\end{array}$ & $\begin{array}{c}-192.48 \\
(0.066)\end{array}$ & $\begin{array}{c}-158.88 \\
(0.39)\end{array}$ & $\begin{array}{l}-228 \\
(0.006)\end{array}$ & $\begin{array}{c}-\mathbf{1 5 3 . 9 1} \\
(-1)\end{array}$ & $\begin{array}{c}-183.65 \\
(0.152)\end{array}$ & $\begin{array}{c}-183.65 \\
(0.158)\end{array}$ \\
\hline Dictator Games CR02 & $\begin{array}{c}-206 \\
(0)\end{array}$ & $\begin{array}{c}-190.48 \\
(0)\end{array}$ & -185.76 & $\begin{array}{c}-166 \\
(0)\end{array}$ & $\begin{array}{c}-166 \\
(0)\end{array}$ & $\begin{array}{c}-293.6 \\
(0)\end{array}$ & $\begin{array}{c}-157.19 \\
(-)\end{array}$ & $\begin{array}{c}-197.84 \\
(0.008)\end{array}$ & -187.34 \\
\hline Response Games CR02, Pl. 1 & $\begin{array}{c}-518.24 \\
(0.344)\end{array}$ & $\begin{array}{c}-672.4 \\
(0.002)\end{array}$ & $\begin{array}{c}-541.28 \\
(0.099)\end{array}$ & $\begin{array}{c}-480.4 \\
(0.506)\end{array}$ & $\begin{array}{c}-544.4 \\
(0.249)\end{array}$ & $\begin{array}{c}-652.16 \\
(0.006)\end{array}$ & $\begin{array}{c}-483.96 \\
(-)\end{array}$ & $\begin{array}{c}-380.77 \\
(0.909)\end{array}$ & $\begin{array}{c}-\mathbf{3 5 4 . 6 6} \\
(0.976)\end{array}$ \\
\hline Response Games CR02, Pl. 2 & $\begin{array}{c}-464.3 \\
(0.015)\end{array}$ & $\begin{array}{c}-516.46 \\
(0.008)\end{array}$ & $\begin{array}{c}-428.46 \\
(0.042)\end{array}$ & $\begin{array}{c}-627.42 \\
(0)\end{array}$ & $\begin{array}{c}-627.42 \\
(0)\end{array}$ & $\begin{array}{c}-547.9 \\
(0.004)\end{array}$ & $\begin{array}{c}-\mathbf{3 4 3 . 3 2} \\
(-)\end{array}$ & $\begin{array}{c}-416.14 \\
(0.117)\end{array}$ & $\begin{array}{c}-434.6 \\
(0.031)\end{array}$ \\
\hline Overall & $\begin{array}{c}-1821.04 \\
(0)\end{array}$ & $\begin{array}{c}-1892.38 \\
(0)\end{array}$ & $\begin{array}{c}-1705.26 \\
(0)\end{array}$ & $\begin{array}{c}-1828.08 \\
(0)\end{array}$ & $\begin{array}{c}-1858.48 \\
(0)\end{array}$ & $\begin{array}{c}-2209.68 \\
(0)\end{array}$ & $\begin{array}{c}-1424.69 \\
(-1)\end{array}$ & $\begin{array}{c}-1623.23 \\
(0.056)\end{array}$ & $\begin{array}{c}-1466.62 \\
(0.356)\end{array}$ \\
\hline
\end{tabular}

Fehr-Schmidt model FS-Full. It improves on FS-Full in four of the five classes of games, which we discuss in more detail shortly. The best-fitting homogeneous model is RRDA, and quite surprisingly, it is the only model that improves upon Ego in this out-of-sample test. As a homogeneous model, ARDA does not fit as well, but it complements RRDA well, as the RRDA-ARDA mixture fits significantly better than RRDA overall.

Across the three sets of dictator and voting games, ARDA, RRDA, and the two reciprocal charity models fit about similarly well. Inequity aversion does substantially worse than these models in these dictator games. As for CR02's response games, ARDA and RRDA predict player 2's behavior rather well, while their predictions for player 1 are rather weak. The strength of RDA, and in particular of RRDA, is therefore to explain both behavior in generalized dictator games and the choices of player 2 in CR02's response games. This set of decisions comprises distributional choices, with and without "contexts" such as a previous choice of a co-player. For this reason, we conclude that the "context dependence" of distributional choice appears to be captured comparably well by reference dependence of altruism.

The strength of charitable reciprocity and inequity aversion, in turn, is to explain the behavior of player 1 in CR02's response games. These choices appear to be characterized by strategic or instrumental reciprocity in the sense of Blanco et al. (2011) and Cabral et al. (2014). Table 3 shows that egoism also does fairly well in predicting the choices of player 1 , and the only homogeneous model improving upon egoism in predicting strategic reciprocity is the reciprocal charity model of Charness and Rabin. Amongst the heterogeneous models, FS-Full captures strategic reciprocity particularly well. It appears that this is to be attributed to its inclusion of egoism. To verify this, we estimated an "RDA-Ego" mixture of $60 \%$ Egoists and $40 \%$ RRDA, i.e. a mixture that substitutes FS inequity aversion (IneqAv) with RRDA. This model fits substantially better than FS-Full, with respect to player 
1 in response games, although the RRDA-ARDA mixture we estimated above does not. These results suggest that distributional choice and strategic reciprocity are governed by different preference systems for a substantial number of players, confirming Blanco et al. (2011) and Cabral et al. (2014).

\section{Conclusion}

In this paper, we experimentally analyzed bargaining under majority voting. The theoretical prediction that majority voting strongly favors the coalition formateur holds under both payoff maximization and weakly concave utilities such as FS inequity aversion and CES altruism. This renders majority rule theoretically unsuitable for facilitating equitably outcomes, but previous experimental results suggest the contrary. The observed equity also resembles similar outcomes in the field (Fréchette et al., 2005a). To ascertain its suitability and allow development for practical use, underlying preferences need be understood.

We theoretically demonstrated how reference dependent altruism (RDA) potentially explains majority bargaining behavior as observed in earlier experiments and the field. Players are largely payoff concerned when their payoff is below their reference point and largely efficiency concerned when their payoff is at or above their reference point. RDA also is simple in that players are primarily payoff concerned and goal oriented, choosing to benefit other players only if their personal goal is reached.

We set up a laboratory experiment with two treatments that, when analyzed in conjunction, sharply separate existing theories and RDA for two kinds of reference points. Thus, we were able to explicitly test whether RDA correctly predicts behavior in majority bargaining. The observed votes and cluster areas of proposals are captured by RDA in a manner that appears to be both qualitatively accurate and quantitatively fitting, with pseudo- $R^{2}$ around $90 \%$. Thus, RDA is capable of capturing behavior in majority bargaining. More generally, RDA appears to be a promising theory of behavior in randomproposer bargaining, i.e. interactions where subjects experience both roles (proposer and responder), where existing models are known to struggle with capturing behavior. Besides majority bargaining as analyzed here, RDA also explains behavior in demand bargaining (Breitmoser and Tan, 2013), in the wide selection of simple distribution and bargaining games of Charness and Rabin (2002), where subject also play in both roles, and in the three-player dictator and voting games of Engelmann and Strobel (2004) and Bolton and Ockenfels (2006), where the ultimate roles are not assigned when decisions are made. 
Clearly, there is much scope for further tests of RDA, but since existing theories of social preferences are known to fail to explain experimental results across this range of interactions, the reported results are rather encouraging. RDA seems to enable substantial progress in jointly explaining bargaining behavior and distributional choice, and in particular in explaining the alleged context dependence of inequity aversion, efficiency concerns, and egoism across in these interactions.

To conclude, this study shows that majority voting is a mechanism that facilitates inequity under self-interest and a variety of social preferences. Nevertheless, equity is observed when other parties in society have the opportunity to be recognized as formateur, suggesting that both formateurs and voters are reference dependent altruistic.

\section{References}

Amemiya, T. (1978). On a two-step estimation of a multivariate logit model. Journal of Econometrics, 8(1):13-21.

Andreoni, J. (1988). Why free ride?: Strategies and learning in public goods experiments. Journal of public Economics, 37(3):291-304.

Andreoni, J. and Miller, J. (2002). "Giving according to GARP: An experimental test of the consistency of preferences for altruism". Econometrica, 70(2):737-753.

Arcidiacono, P. and Jones, J. B. (2003). Finite mixture distributions, sequential likelihood and the em algorithm. Econometrica, 71(3):933-946.

Auger, A., Hansen, N., Zerpa, J. P., Ros, R., and Schoenauer, M. (2009). Experimental comparisons of derivative free optimization algorithms. Experimental Algorithms, pages $3-15$.

Baron, D. and Kalai, E. (1993). The simplest equilibrium of a majority rule division game. Journal of Economic Theory, 61(2):290-301.

Baron, D. P. and Ferejohn, J. A. (1989). Bargaining in legislatures. American Political Science Review, 83(4):1181-1206.

Biernacki, C., Celeux, G., and Govaert, G. (1999). An improvement of the nec criterion for assessing the number of clusters in a mixture model. Pattern Recognition Letters, 20(3):267-272.

Biernacki, C., Celeux, G., and Govaert, G. (2000). Assessing a mixture model for clustering with the integrated completed likelihood. Pattern Analysis and Machine Intelligence, IEEE Transactions on, 22(7):719-725. 
Blanco, M., Engelmann, D., and Normann, H. T. (2011). A within-subject analysis of other-regarding preferences. Games and Economic Behavior, 72(2):321-338.

Bolton, G. E. and Ockenfels, A. (2006). Inequality aversion, efficiency, and maximin preferences in simple distribution experiments: comment. The American economic review, 96(5):1906-1911.

Breitmoser, Y. and Tan, J. H. (2013). Reference dependent altruism in demand bargaining. Journal of Economic Behavior and Organization, 92:127-140.

Breitmoser, Y., Tan, J. H., and Zizzo, D. J. (2010). Understanding perpetual R\&D races. Economic Theory, 44(3):445-467.

Cabral, L., Ozbay, E. Y., and Schotter, A. (2014). Intrinsic and instrumental reciprocity: An experimental study. Games and Economic Behavior, 87:100-121.

Cappelen, A. W., Hole, A. D., Sørensen, E. Ø., and Tungodden, B. (2007). The pluralism of fairness ideals: An experimental approach. American Economic Review, 97(3):818827.

Charness, G. and Rabin, M. (2002). Understanding social preferences with simple tests. Quarterly Journal of Economics, 117(3):817-869.

Compte, O. and Jehiel, P. (2010). Bargaining and majority rules: A collective search perspective. Journal of Political Economy, 118(2):189-221.

Cox, J. C., Friedman, D., and Gjerstad, S. (2007). A tractable model of reciprocity and fairness. Games and Economic Behavior, 59(1):17-45.

Diermeier, D. and Gailmard, S. (2006). Self-interest, inequality, and entitlement in majoritarian decision-making. Quarterly Journal of Political Science, 1(4):327-350.

Drouvelis, M., Montero, M., and Sefton, M. (2010). Gaining power through enlargement: Strategic foundations and experimental evidence. Games and Economic Behavior, 69(2):274-292.

Engelmann, D. and Strobel, M. (2004). Inequality aversion, efficiency, and maximin preferences in simple distribution experiments. American Economic Review, 94(4):857869.

Eraslan, H. (2002). Uniqueness of stationary equilibrium payoffs in the baron-ferejohn model. Journal of Economic Theory, 103(1):11-30.

Fehr, E. and Schmidt, K. M. (1999). A theory of fairness, competition, and cooperation. Quarterly Journal of Economics, 114(3):817-868.

Fehr, E. and Schmidt, K. M. (2010). On inequity aversion: a reply to binmore and shaked. Journal of economic behavior \& organization, 73(1):101-108. 
Fischbacher, U. (2007). z-tree: Zurich toolbox for ready-made economic experiments. Experimental Economics, 10(2):171-178.

Fréchette, G., Kagel, J. H., and Morelli, M. (2005a). Behavioral identification in coalitional bargaining: An experimental analysis of demand bargaining and alternating offers. Econometrica, 73(6):1893-1937.

Fréchette, G., Kagel, J. H., and Morelli, M. (2005b). Nominal bargaining power, selection protocol, and discounting in legislative bargaining. Journal of Public Economics, 89(8):1497-1517.

Fréchette, G., Kagel, J. H., and Morelli, M. (2012). Pork versus public goods: an experimental study of public good provision within a legislative bargaining framework. Economic Theory, 49:779-800.

Gneiting, T. and Raferty, A. (2007). Strictly proper scoring rules, prediction, and estimation. Journal of the American Statistical Association, 102(477):359-378.

Goeree, J. K., Holt, C. A., and Laury, S. K. (2002). Private costs and public benefits: unraveling the effects of altruism and noisy behavior. Journal of Public Economics, 83(2):255-276.

Goeree, J. K., Holt, C. A., and Palfrey, T. R. (2016). Quantal Response Equilibrium: A stochastic theory of games. Princeton.

Knight, B. (2005). Estimating the value of proposal power. American Economic Review, 95(5):1639-1652.

Knight, B. (2008). Legislative representation, bargaining power and the distribution of federal funds: evidence from the us congress. The Economic Journal, 118(532):17851803.

Kőszegi, B. and Rabin, M. (2007). Reference-dependent risk attitudes. American Economic Review, 97(4):1047-1073.

Levitt, S. D. and Snyder Jr, J. M. (1997). The impact of federal spending on House election outcomes. Journal of Political Economy, 105(1):30-53.

McCarty, N. M. (2000). Presidential pork: Executive veto power and distributive politics. American Political Science Review, 94(01):117-129.

McFadden, D. (1978). Modelling the choice of residential location. In Karlqvist, A., Lundqvist, L., Snickars, F., and Weibull, J., editors, Spatial interaction theory and planning models, pages 75-96. North Holland, Amsterdam.

McFadden, D. (1984). Econometric analysis of qualitative response models. Handbook of econometrics, 2:1395-1457. 
McKelvey, R. D. and Palfrey, T. R. (1995). Quantal response equilibria for normal form games. Games and Economic Behavior, 10(1):6-38.

McKelvey, R. D. and Palfrey, T. R. (1998). Quantal response equilibria for extensive form games. Experimental Economics, 1(1):9-41.

McLachlan, G. and Peel, D. (2000). Finite mixture models, volume 299. WileyInterscience.

Montero, M. (2007). Inequity aversion may increase inequity. The Economic Journal, 117(519):192-204.

Montero, M., Sefton, M., and Zhang, P. (2008). Enlargement and the balance of power: an experimental study. Social Choice and Welfare, 30(1):69-87.

Moré, J. J. and Wild, S. M. (2009). Benchmarking derivative-free optimization algorithms. SIAM Journal on Optimization, 20(1):172-191.

Ng, Y.-K. (2000). Efficiency, equality and public policy: With a case for higher public spending. Springer.

Okada, A. (2011). Coalitional bargaining games with random proposers: Theory and application. Games and Economic Behavior, 73(1):227 - 235.

Okun, A. (1975). Efficiency and equity: The big tradeoff. Washington, DC: Brookings Institution.

Powell, M. (2008). Developments of newuoa for minimization without derivatives. IMA journal of numerical analysis, 28(4):649.

Schwarz, G. (1978). Estimating the dimension of a model. Annals of Statistics, 6(2):461464.

Selten, R. (1998). Axiomatic characterization of the quadratic scoring rule. Experimental Economics, 1(1):43-62.

Shenoy, P. P. (1980). On committee decision making: a game theoretical approach. Management Science, 26(4):387-400.

Snyder Jr, J. M., Ting, M. M., and Ansolabehere, S. (2005). Legislative bargaining under weighted voting. American Economic Review, 95(4):981-1004.

Vuong, Q. H. (1989). Likelihood ratio tests for model selection and non-nested hypotheses. Econometrica, 57(2):307-333.

\section{Appendix: Out-of-sample predictions of the analyzed mod- els}


Table 5: Predictions for the Engelmann-Strobel, Bolton-Ockenfels and Charness-Rabin games

\begin{tabular}{|c|c|c|c|c|c|c|c|c|c|c|c|c|c|}
\hline & \multicolumn{4}{|c|}{ Observations } & \multicolumn{8}{|c|}{ Predictions (Probability of $a_{1}$ ) } & \multirow[b]{2}{*}{ RDA-Ego } \\
\hline & \#Subj & $a_{1}$ & $a_{2}$ & $a_{3}$ & Ego & ARDA & RRDA & RecChar & CR-Full & IneqAv & RDA & FS-Full & \\
\hline \multicolumn{14}{|c|}{ Predictions for Dictator Games in Engelmann and Strobel (2004) } \\
\hline Tax-F & 68 & 0.84 & 0.1 & 0.06 & 1 & 1 & 1 & 1 & 1 & 1 & 1 & 1 & 1 \\
\hline Tax-Fx & 30 & 0.87 & 0.07 & 0.07 & 1 & 1 & 1 & 1 & 1 & 1 & 1 & 1 & 1 \\
\hline Tax-Ex & 30 & 0.4 & 0.17 & 0.43 & 0 & 1 & 1 & 0 & 0 & 0 & 1 & 0 & 0.4 \\
\hline Envy-N & 30 & 0.7 & 0.27 & 0.03 & 0 & 1 & 1 & 1 & 1 & 0 & 1 & 0 & 0.4 \\
\hline Envy-Nyi & 30 & 0.6 & 0.17 & 0.23 & 0 & 1 & 1 & 1 & 1 & 0 & 1 & 0 & 0.4 \\
\hline RPG-R & 30 & 0.27 & 0.2 & 0.53 & 1 & 1 & 1 & 1 & 1 & 1 & 1 & 1 & 1 \\
\hline RPG-P & 30 & 0.6 & 0.07 & 0.33 & 0 & 1 & 1 & 1 & 1 & 0 & 1 & 0 & 0.4 \\
\hline RPG-Ey & 30 & 0.4 & 0.23 & 0.37 & 0 & 1 & 1 & 0 & 0 & 0 & 1 & 0 & 0.4 \\
\hline
\end{tabular}

Predictions for Voting Games in Bolton and Ockenfels (2006)

Player 1

$\begin{array}{llll}\text { Straight Game I } & 24 & 0.25 & 0.75\end{array}$

Straight Game II $\quad 24 \quad 0.33 \quad 0.67$

Straight Game III $\quad 24 \quad 0.21 \quad 0.79$

$\begin{array}{llll}\text { Equal Game I } & 24 & 0.12 & 0.88\end{array}$

$\begin{array}{llll}\text { Equal Game II } \quad 24 & 0.25 & 0.75\end{array}$

$\begin{array}{llll}\text { Equal Game III } \quad 24 & 0.17 & 0.83\end{array}$

Player 2

Straight Game II $\quad 24 \quad 0.88 \quad 0.12$

$\begin{array}{llll}\text { Equal Game II } \quad 24 & 0.92 & 0.08\end{array}$

Player 3

Straight Game II $\quad 24 \quad 0.38 \quad 0.62$

$\begin{array}{llll}\text { Equal Game II } \quad 24 & 0.25 & 0.75\end{array}$

Players 2 and 3

Straight Game I $\quad 48 \quad 0.48 \quad 0.52$

Straight Game III $\quad 48 \quad 0.88 \quad 0.12$

$\begin{array}{llll}\text { Equal Game I } & 24 & 0.17 & 0.83\end{array}$

Equal Game III $\quad 24 \quad 0.85 \quad 0.15$

Predictions for Dictator Games in Charness and Rabin (2002)

\begin{tabular}{lcccccccccccc} 
DG2-Berk29 & 26 & 0.31 & 0.69 & 1 & 0 & 1 & 0 & 0 & 1 & 0.55 & 1 \\
DG2-Barc2 & 48 & 0.52 & 0.48 & 1 & 1 & 1 & 1 & 1 & 1 & 1 & 1 \\
DG2-Berk17 & 32 & 0.5 & 0.5 & 1 & 1 & 1 & 1 & 1 & 1 & 1 & 1 \\
DG2-Berk23 & 36 & 1 & 0 & 1 & 1 & 1 & 1 & 1 & 0 & 1 & 0.6 \\
DG2-Barc8 & 36 & 0.67 & 0.33 & 1 & 0 & 1 & 1 & 1 & 1 & 0.55 & 1 \\
DG2-Berk15 & 22 & 0.27 & 0.73 & 1 & 0 & 0 & 0 & 0 & 0 & 0 & 0.6 \\
DG2-Berk26 & 32 & 0.78 & 0.22 & 1 & 1 & 1 & 1 & 1 & 0 & 1 & 0.6 \\
DG3-Berk24 & 24 & 0.54 & 0.46 & 1 & 1 & 1 & 1 & 1 & 1 & 1 & 1 \\
\hline
\end{tabular}

Note: The action labeled " $a_{1}$ " corresponds with $A$ in ES04 and BO06, and with $O, L$ in CR; " $a_{2}$ " corresponds with $B$ in ES04 and BO06, and $E, R$ in CR02; " $a_{3}$ " corresponds with "C" in ES04. The listed predictions concern the probability of $a_{1}$; the remaining probabilities follow immediately considering that no theory uniquely predicts $B$ in ESO4. 


\begin{tabular}{|c|c|c|c|c|c|c|c|c|c|c|c|c|}
\hline & \#Subj & $a_{1}$ & $a_{2} \quad a_{3}$ & Ego & ARDA & RRDA & RecChar & CR-Full & IneqAv & RDA & FS-Full & RDA-Ego \\
\hline \multicolumn{13}{|c|}{ Predictions for Player 1 of Response Games in Charness and Rabin (2002) } \\
\hline RG2-Barc7 & 36 & 0.47 & 0.53 & 0 & 0 & 0 & 0 & 0 & 0 & 0 & 0 & 0 \\
\hline RG2-Barc5 & 36 & 0.39 & 0.61 & 0 & 0 & 1 & 1 & 1 & 1 & 0.55 & 0.4 & 0.4 \\
\hline RG2-Berk28 & 32 & 0.5 & 0.5 & 0 & 1 & 1 & 0 & 0 & 0 & 1 & 0 & 0.4 \\
\hline RG2-Berk32 & 26 & 0.85 & 0.15 & 1 & 1 & 0 & 1 & 1 & 0 & 0.45 & 0.6 & 0.6 \\
\hline RG2s-Barc3 & 42 & 0.74 & 0.26 & 1 & 0 & 0 & 1 & 1 & 0 & 0 & 0.6 & 0.6 \\
\hline RG2s-Barc4 & 42 & 0.83 & 0.17 & 1 & 1 & 1 & 1 & 1 & 0 & 1 & 0.6 & 1 \\
\hline RG2s-Berk21 & 36 & 0.47 & 0.53 & 1 & 0 & 0 & 1 & 1 & 0 & 0 & 0.6 & 0.6 \\
\hline RG2s-Barc6 & 36 & 0.92 & 0.08 & 1 & 0 & 1 & 1 & 1 & 1 & 0.55 & 1 & 1 \\
\hline RG2s-Barc9 & 36 & 0.69 & 0.31 & 1 & 0 & 0 & 0 & 0 & 0 & 0 & 0.6 & 0.6 \\
\hline RG2s-Berk25 & 32 & 0.62 & 0.38 & 1 & 0 & 0 & 0 & 0 & 0 & 0 & 0.6 & 0.6 \\
\hline RG2s-Berk19 & 32 & 0.56 & 0.44 & 1 & 0 & 0 & 0 & 0 & 0 & 0 & 0.6 & 0.6 \\
\hline RG2s-Berk14 & 22 & 0.68 & 0.32 & 1 & 1 & 1 & 1 & 1 & 0 & 1 & 0.6 & 1 \\
\hline RG2s-Barc1 & 44 & 0.96 & 0.04 & 1 & 0 & 1 & 1 & 1 & 1 & 0.55 & 1 & 1 \\
\hline RG2s-Berk13 & 22 & 0.86 & 0.14 & 1 & 0 & 1 & 1 & 1 & 1 & 0.55 & 1 & 1 \\
\hline RG2s-Berk18 & 32 & 0 & 1 & 0 & 0 & 0 & 0 & 1 & 0 & 0 & 0 & 0 \\
\hline RG2h-Barc11 & 35 & 0.54 & 0.46 & 0 & 1 & 0 & 0 & 0 & 0 & 0.45 & 0 & 0 \\
\hline RG2h-Berk32 & 36 & 0.39 & 0.61 & 0 & 1 & 0 & 0 & 0 & 0 & 0.45 & 0 & 0 \\
\hline RG2h-Berk27 & 32 & 0.41 & 0.59 & 0 & 0 & 0 & 1 & 1 & 1 & 0 & 0.4 & 0 \\
\hline RG2h-Berk31 & 26 & 0.73 & 0.27 & 0 & 1 & 1 & 1 & 1 & 1 & 1 & 0.4 & 0.4 \\
\hline RG2h-Berk30 & 26 & 0.77 & 0.23 & 0 & 1 & 1 & 1 & 1 & 0 & 1 & 0 & 0.4 \\
\hline RG3-Berk16 & 15 & 0.93 & 0.07 & 0 & 1 & 1 & 1 & 1 & 1 & 1 & 0.4 & 0.4 \\
\hline RG3-Berk20 & 21 & 0.95 & 0.05 & 0 & 1 & 1 & 1 & 1 & 1 & 1 & 0.4 & 0.4 \\
\hline \multicolumn{13}{|c|}{ Predictions for Player 2 of Response Games in Charness and Rabin (2002) } \\
\hline RG2-Barc7 & 36 & 0.06 & 0.94 & 1 & 0 & 1 & 0.5 & 0.5 & 1 & 0.55 & 1 & 1 \\
\hline RG2-Barc5 & 36 & 0.33 & 0.67 & 1 & 0 & 1 & 0 & 0 & 1 & 0.55 & 1 & 1 \\
\hline RG2-Berk28 & 32 & 0.34 & 0.66 & 0 & 0 & 0 & 0 & 0 & 0 & 0 & 0 & 0 \\
\hline RG2-Berk32 & 26 & 0.35 & 0.65 & 0 & 0 & 0 & 0 & 0 & 0 & 0 & 0 & 0 \\
\hline RG2s-Barc3 & 42 & 0.62 & 0.38 & 1 & 0 & 1 & 1 & 1 & 1 & 0.55 & 1 & 1 \\
\hline RG2s-Barc4 & 42 & 0.62 & 0.38 & 1 & 1 & 1 & 1 & 1 & 1 & 1 & 1 & 1 \\
\hline RG2s-Berk21 & 36 & 0.61 & 0.39 & 1 & 0 & 1 & 1 & 1 & 1 & 0.55 & 1 & 1 \\
\hline RG2s-Barc6 & 36 & 0.75 & 0.25 & 1 & 0 & 1 & 0 & 0 & 1 & 0.55 & 1 & 1 \\
\hline RG2s-Barc9 & 36 & 0.94 & 0.06 & 1 & 1 & 1 & 0 & 0 & 1 & 1 & 1 & 1 \\
\hline RG2s-Berk25 & 32 & 0.81 & 0.19 & 1 & 1 & 1 & 0 & 0 & 1 & 1 & 1 & 1 \\
\hline RG2s-Berk19 & 32 & 0.22 & 0.78 & 1 & 0 & 0 & 0 & 0 & 0 & 0 & 0.6 & 0.6 \\
\hline RG2s-Berk14 & 22 & 0.45 & 0.55 & 1 & 1 & 1 & 1 & 1 & 0 & 1 & 0.6 & 1 \\
\hline RG2s-Barc1 & 44 & 0.93 & 0.07 & 1 & 0 & 1 & 0 & 0 & 1 & 0.55 & 1 & 1 \\
\hline RG2s-Berk13 & 22 & 0.82 & 0.18 & 1 & 0 & 1 & 0 & 0 & 1 & 0.55 & 1 & 1 \\
\hline RG2s-Berk18 & 32 & 0.44 & 0.56 & 1 & 1 & 1 & 1 & 1 & 0 & 1 & 0.6 & 1 \\
\hline RG2h-Barc11 & 35 & 0.89 & 0.11 & 1 & 1 & 1 & 1 & 1 & 1 & 1 & 1 & 1 \\
\hline RG2h-Berk32 & 36 & 0.97 & 0.03 & 1 & 1 & 1 & 1 & 1 & 1 & 1 & 1 & 1 \\
\hline RG2h-Berk27 & 32 & 0.91 & 0.09 & 1 & 1 & 1 & 1 & 1 & 0 & 1 & 0.6 & 1 \\
\hline RG2h-Berk31 & 26 & 0.88 & 0.12 & 1 & 1 & 1 & 1 & 1 & 0 & 1 & 0.6 & 1 \\
\hline RG2h-Berk30 & 26 & 0.88 & 0.12 & 1 & 1 & 1 & 1 & 1 & 0 & 1 & 0.6 & 1 \\
\hline RG3-Berk16 & 15 & 0.8 & 0.2 & 0 & 0 & 0 & 0 & 0 & 0 & 0 & 0 & 0 \\
\hline RG3-Berk20 & 21 & 0.86 & 0.14 & 1 & 1 & 1 & 0 & 0 & 1 & 1 & 1 & 1 \\
\hline
\end{tabular}




\section{Supplementary material Why should majority voting be unfair?}

\author{
Yves Breitmoser \\ Humboldt University Berlin
}

\author{
Jonathan H.W. Tan \\ University of Nottingham
}

\section{Overview}

Section 2 contains the experimental instructions for the treatment PB95. Section 3 provides basic strategy estimates and shows that stationarity and truncation consistency are not violated significantly. Section 4 describes the structural model used in the analysis (stationary nested logit equilibrium). Sections 5 and 6 contain the Tables with goodness-of-fit measures and parameter estimates for all models reported in the paper and a few additional models that we estimated to verify the robustness of the conclusions drawn in the paper. These tables are directly based on the output of the scripts that we used to run the optimization, which avoids the possibility of mistakes due to retyping the results.

\section{Contents}

List of Tables $\quad 2$

1 Overview of tables 2

2 Experimental instructions for $P B 95 \quad 4$

3 Basic characteristics of subjects' strategies $\quad 5$

4 Stationary (nested) logit equilibrium $\quad 7$

5 Overview model fit (BIC) 10

6 Parameter estimates 11 


\section{List of Tables}

1 Goodness of fits of logit and nested logit models . . . . . . . . . 10

2 Goodness of fits of mixed multi-type models . . . . . . . . . . 10

3 Goodness of fits of heterogenous models . . . . . . . . . . . 10

4 Parameter estimates for logit and nested logit models without mix-

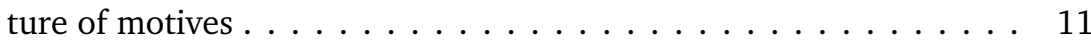

5 Two-type mixed models . . . . . . . . . . . . . . . . . 12

6 Three-type mixed models . . . . . . . . . . . . . . . . . . . . . 14

$7 \quad$ Four-type mixed model . . . . . . . . . . . . . . . . . . . 15

8 Heterogenous models (proposer and voters may have different preferences). Does not improve goodness-of-fit . . . . . . . . . . 16

9 Estimates for models with time-dependent parameters. All parameters $x \in\{\lambda, \alpha, \beta\}$ have an initial value and a time dependency parameter $\kappa_{x}$; the parameter value in game $g$ is $x+\kappa_{x} \cdot g$. The goodness-of-fit does not improve significantly over the constant models, suggesting that parameters do not change significantly. . . 18

\section{Overview of tables}

- Tables 1 and 4 contain the ICL-BIC measures for the goodness-of-fit and the parameter estimates (respectively) of the models where all components are based on the same social motive.

- Tables 2, 5, 6, and 7 contains the ICL-BIC measures and parameter estimates of the models with up to four components and mixtures of social motives.

- Tables 3 and 8 contain the ICL-BIC measures for the goodness-of-fit and the parameter estimates (respectively) of the heterogenous models where proposers and voters may have different motives.

- Table 9 contains the estimates of models with time-dependent parameters.

The key used to distinguished these models is self-explanatory and equivalent to the one used in the paper. The notation of the RDA utility functions is slightly 
different than in the paper. Here, they are defined as follows.

$$
\begin{aligned}
& U_{i}^{A R D A}(\mathbf{x})=x_{i}+\alpha \sum_{j \neq i} x_{j} \cdot I_{x_{i} \geq x_{i}^{*}}+\beta \sum_{j \neq i} x_{j} \cdot I_{x_{j}<x_{i}^{*}} \\
& U_{i}^{R R D A}(\mathbf{x})=x_{i}-\alpha \sum_{j \neq i} x_{j} \cdot I_{x_{i}<x_{j}}-\beta \sum_{j \neq i} x_{j} \cdot I_{x_{i} \geq x_{j}},
\end{aligned}
$$




\section{Experimental instructions for PB95}

The following is a literal translation of the experimental instructions for PB95. The original instructions and control questionnaires (in German) for all treatments are available from the authors.

\section{Instructions}

You are participating in an experiment on decision making. The experiment is divided into 10 stages. In each stage you are assigned to one of four groups by the computer, with 3 participants per group (including you). After each stage you are assigned to a new group. You are paid based on a randomly chosen "payment stage." You are paid your payment from this stage in Euros. In addition, you get 4 Euros that are independent of your actions.

Your task In each stage, 24 Euros are to be allocated. First, one participant is assigned the $A$ role, and the other two group members are assigned the $B$ role. These assignments are random, and all group members have the same probability of being assigned the $A$ role. The $A$ participant makes a proposal on how to allocate the 24 Euros. Then, the $B$ participants vote on the proposal, with either "yes" or "no." If at least one $B$ participant agrees with the proposal (i.e. votes "yes"), then the allocation is implemented and the stage ends. If no $B$ participant votes "yes," then

- with $95 \%$ probability and new round starts, where again a player is assigned the $A$ role randomly, and

- with $5 \%$ probability the current stage ends. In this case, all participants obtain 0 Euros.

General remarks In each stage the three members of a group are referred to as Participant 1, Participant 2, and Participant 3. The numbering is random, and it is made whenever a new group is formed (i.e. in the beginning of each stage). Thus, it may happen that you are referred to as Participant 3 in one stage and as Participant 1 in another. The numbering is held constant for the duration of a stage. The assignment of $A$ and $B$ roles is independent of the numbering, i.e. in the first round of a stage Participant 2 may be assigned the $A$ role and in a possible second round this may be Participant 3. It may also happen that one of the participants is assigned the $A$ role in two or more consecutive rounds (while multiple successive assignments are relatively unlikely). 
As for the allocation proposed by the $A$ participant, the following is to be acknowledged. No participant may be allocated less than 0 Euros, no one may be allocated more than 24 Euros, and in total no more than 24 Euros can be allocated. It is not mandatory that the whole 24 Euros are allocated. It is possible to allocate fractional numbers such as " 0.80 " (= 0 Euros and 80 cents). Fractions of a cent may not be allocated.

\section{Basic characteristics of subjects' strategies}

We estimate the strategies by considering regression models that include a range of independent variables that may be relevant for the strategic task at hand, i.e. we include the variables that should be strategically relevant by theory and others that could have been relevant for the subjects. We control for the game number minus 1 within the session $(=G)$, for the round number minus 1 within the game $(=R)$, and for the interdependence induced by the experimental design (by considering two levels of random effects, "Session" and "Subjects within Session"). The proposals are denoted as $\left(x_{p}, x_{h}, x_{l}\right)$ as in the paper; the components refer to the proposer share, the higher offer to a voter, the lower offer to a voter (respectively). In case of $x_{l}$, we also control for an interaction with $x_{h}$. Significance at the $5 \%$ level is denoted by ${ }^{*}$ and significance at the $1 \%$ level by ${ }^{* *}$. Due to the multiplicity of tests made in this section, we require significance at the $1 \%$ level for significant results. ${ }^{1}$

$$
\begin{aligned}
& x_{p}=\underset{(0.4708)}{11.121^{* *}} \underset{(0.6367)}{0.7479 \cdot G^{-1}}-\underset{(0.3637)}{0.6157 \cdot R} \\
& x_{h}=\underset{(0.3307)}{9.1337^{* *}}-\underset{(0.4974)}{1.7445^{* *}} \cdot G^{-1}+\underset{(0.2844)}{0.2521} \cdot R \\
& x_{l}=\underset{(0.8687)}{6.8040^{* *}}+\underset{(0.6272)}{0.8941} \cdot G^{-1}+\underset{(0.3506)}{0.4254 \cdot R}-\underset{(0.0816)}{0.3535^{* *}} \cdot x_{h}
\end{aligned}
$$

The intercept represents the initial proposal, i.e. the average proposal in the first round of the first game (aside from the interaction with $x_{h}$ ). The initial value of $x_{h}$ is about as predicted, but it increases significantly (albeit small in absolute terms) as the subjects gain experience. In addition, there is a strong crowding-out effect between security in vote buying (increasing $x_{h}$ ) and non-strategic giving to the third player $\left(x_{l}\right)$. The round index $R$ in Eqs. (3)-(5) is insignificant, indicating that stationarity is not significantly violated.

Result 1. There is no significant round effect in the proposal functions in PB95, which indicates that stationarity is not violated.

\footnotetext{
${ }^{1}$ This corresponds approximately with both the Bonferroni correction and the Sidak correction for 5-6 tests where the probability of a false positive is supposed to be at 0.05.
} 
In $P B O 0$, the estimated proposal functions differ only slightly (note that the round number $R$ is dropped, since there is just a single round in these games).

$$
\begin{aligned}
& x_{p}=\underset{(0.5379)}{11.187^{* *}-\underset{(0.7827)}{3.2105^{* *}} \cdot G^{-1}} \\
& x_{h}=\underset{(0.3891)}{9.5751^{* *}-\underset{(0.6731)}{2.5177^{* *}} \cdot G^{-1}} \\
& x_{l}=\underset{(1.1133)}{4.4923^{* *}}+\underset{(0.8666)}{2.5508^{* *}} \cdot G^{-1}-\underset{(0.1003)}{0.1147 \cdot x_{h}}
\end{aligned}
$$

Compared to PB95, there is no significant crowding out between $x_{h}$ and $x_{l}$, and the increase of $x_{p}$ and $x_{h}$ as the subjects gain experience is sharper, again at the expense of the non-strategic donation $x_{l}$ toward the third player. ${ }^{2}$

To ascertain truncation consistency, we test whether the proposal functions estimated above, Eqs. (3)-(5) and Eqs. (6)-(8), differ significantly. To this end, we compare the model where the proposal function coefficients depend on treatment (PB95 or PBO0) with the simpler model where the coefficients do not depend on treatment. In likelihood-ratio tests, the differences are insignificant at the .01 level in all three dimensions, but they are close to that threshold with respect to $x_{l}$ (the $p$-values of the likelihood-ratio tests are $p=.064$ for $x_{p}, p=.24$ for $x_{h}$, and $p=.011$ for $x_{l}$ ). Also in view of the non-parametric tests supporting Result 3.1, we conclude that the proposal functions do not violate truncation consistency, especially with respects to $x_{p}$ and $x_{h}$.

Result 2. Proposal functions do not differ significantly between PB95 and PB00, which indicates that truncation consistency is not violated.

We now turn to the voting functions. We model the voting decisions using binomial logit regression with random effects as described above. We consider $G$, $R$, the own payoff $x_{i}$ as proposed, the proposer's payoff $x_{p}$, an indicator $I_{C P}$ that is 1 iff $x_{i} \geq 7.60$ (which is the expected continuation payoff), and indicator $I_{h}$ that is 1 iff one has the high payoff under the proposal in the sense $x_{i}=\max \left\{x_{1}, x_{2}\right\}$. Theoretically, only $I_{C P}$ should be significant. The estimated voting function in PB95 is (where $\hat{=}$ represents the logit link)

$$
\begin{aligned}
\sigma_{v} \hat{=}-\underset{(0.7440)}{2.6013^{* *}} & +\underset{(0.5002)}{1.7477^{* *}} \cdot G^{-1}+\underset{(0.2797)}{0.1747 \cdot R}+\underset{(0.3812)}{1.6930^{* *}} \cdot I_{C P} \\
& +\underset{(0.0919)}{0.5899^{* *}} \cdot x_{i}-\underset{(0.0506)}{0.2647^{* *}} \cdot x_{p}+\underset{(0.3931)}{1.0692^{* *}} \cdot I_{h}
\end{aligned}
$$

\footnotetext{
${ }^{2}$ The fact that these effects do not add up to 0 numerically relates to the observation that the subjects get better in hitting the $€ 24$ available overall as the sessions progress.
} 
and the voting function in $\mathrm{PBOO}$ is

$$
\begin{aligned}
& \sigma_{v} \hat{=}-\underset{(1.3766)}{4.6670^{* *}}+\underset{(1.0606)}{2.6185^{*} \cdot G^{-1}}+\underset{(0.8251)}{3.1550^{* *} \cdot I_{C P}} \\
& +\underset{(0.1588)}{0.4891^{* *}} \cdot x_{i}-\underset{(0.0962)}{0.0582 \cdot x_{p}}-\underset{(0.8379)}{0.9085} \cdot I_{h} .
\end{aligned}
$$

Result 3. There is no significant round effect in the voting functions in PB95, which indicates that stationarity is not violated.

The acceptance probability in $P B 95$ depends negatively on the proposer's payoff $x_{p}$ and on whether $x_{i} \geq x_{j}$ (i.e. that one has been offered the high payoff), suggesting fairness-like concerns albeit not the type predicted by inequity aversion. The hypothesis that the coefficients of these voting functions equate between the treatments using likelihood-ratio tests cannot be rejected at the maintained .01 level $(p=.026)$.

Result 4. Voting functions in PB95 and PB00 do not differ significantly, which indicates that truncation consistency is not violated.

\section{Stationary (nested) logit equilibrium}

Given a utility function $u_{i}: \mathbb{R}^{N} \rightarrow \mathbb{R}$ for player $i \in N$ and well-defined continuation strategies, let $v_{i}(\mathbf{x})$ denote the expected utility of $i$ as a proposer when proposing $\mathbf{x} \in \mathbf{X}$. Player $i$ chooses the proposal to maximize the random utility $\tilde{v}_{i}(\mathbf{x})=v_{i}(\mathbf{x})+$ $\epsilon_{i, \mathbf{x}}$, where $\epsilon_{i, \mathbf{x}}$ has generalized extreme value (GEV) distribution (McFadden, 1978). This model yields the family of GEV proposal functions. If $\left(\epsilon_{i, \mathbf{x}}\right)$ have extreme value distribution, multinomial logit choices result, i.e.

$$
\sigma_{i}(\mathbf{x})=\exp \left\{\lambda \cdot v_{i}(\mathbf{x})\right\} / \sum_{\tilde{\mathbf{x}} \in \mathbf{X}} \exp \left\{\lambda \cdot v_{i}(\tilde{\mathbf{x}})\right\} \quad \forall \mathbf{x} \in \mathbf{X} .
$$

To define the nesting structure in nested logit equilibrium, let $\tilde{u}$ denote the continuation utilities (which is symmetric between players). Two proposals $\mathbf{x}^{\prime}, \mathbf{x}^{\prime \prime} \in$ $\mathbf{X}$ are in the same subset $\mathbf{Y} \in \overline{\mathbf{Y}}$ if and only if $u_{i}\left(\mathbf{x}^{\prime}\right) \geq \tilde{u} \Leftrightarrow u_{i}\left(\mathbf{x}^{\prime \prime}\right) \geq \tilde{u}$ for $i=1,2$. Given $\mathbf{Y}$, two proposals $\mathbf{x}^{\prime}, \mathbf{x}^{\prime \prime} \in \mathbf{Y}$ are in the same subset $\mathbf{Z} \in \overline{\mathbf{Z}}(\mathbf{Y})$ if and only if $\left\lfloor x_{i}^{\prime} / 2\right\rfloor=\left\lfloor x_{i}^{\prime \prime} / 2\right\rfloor$ for $i=1,2$.

Now, we can define the nested logit choice probability (McFadden, 1984) of proposal $\mathbf{x}=\left(x_{p}, x_{1}, x_{2}\right)$. Let $u_{1}(\mathbf{x})$ and $u_{2}(\mathbf{x})$ denote the respective utilities of voter 1 and 2 . The probability of choosing $\mathbf{x} \in \mathbf{X}$ is

$$
\sigma_{i}(\mathbf{x})=Q(\mathbf{x} \mid \mathbf{Z}) \cdot Q(\mathbf{Z} \mid \mathbf{Y}) \cdot Q(\mathbf{Y})
$$


for $\mathbf{x} \in \mathbf{Z}, \mathbf{Z} \in \overline{\mathbf{Z}}(\mathbf{Y})$, and $\mathbf{Y} \in \overline{\mathbf{Y}}$, with

$$
\begin{array}{rlrl}
Q(\mathbf{x} \mid \mathbf{Z}) & =\exp \left\{\lambda^{p} \cdot v_{i}(\mathbf{x})\right\} / p_{\mathbf{Z}} & p_{\mathbf{Z}} & =\sum_{\tilde{\mathbf{x}} \in \mathbf{Z}} \exp \left\{\lambda^{p} \cdot v_{i}(\tilde{\mathbf{x}})\right\} \\
Q(\mathbf{Z} \mid \mathbf{Y}) & =\exp \left\{\rho^{\prime} \cdot \ln p_{\mathbf{Z}}\right\} / p_{\mathbf{Y}} & p_{\mathbf{Y}} & =\sum_{\tilde{\mathbf{Z}} \in \overline{\mathbf{Z}}(\mathbf{Y})} \exp \left\{\rho^{\prime} \cdot \ln p_{\tilde{\mathbf{Z}}}\right\} \\
Q(\mathbf{Y}) & =\exp \left\{\rho^{\prime \prime} \cdot \ln p_{\mathbf{Y}}\right\} / p & p & =\sum_{\tilde{\mathbf{Y}} \in \overline{\mathbf{Y}}} \exp \left\{\rho^{\prime \prime} \cdot \ln p_{\tilde{\mathbf{Y}}}\right\},
\end{array}
$$

where $\left(\lambda^{p}, \rho^{\prime}, \rho^{\prime \prime}\right)$ are precision and interdependence parameters. ${ }^{3}$ Multinomial logit results if $\rho^{\prime}=\rho^{\prime \prime}=1$, while violations of multinomiality result for $\rho^{\prime}, \rho^{\prime \prime} \in$ $(0,1)$.

Following the majority bargaining literature, we focus on symmetric equilibria. That is, all players have the same preferences and the same proposal and voting functions. Symmetric (stationary) QREs of our random-proposer games are fully characterized by a duple $\left(\sigma_{p}, \sigma_{v}\right)$, where $\sigma_{p} \in \Delta(\mathbf{X})$ is the proposal function (of each player), and $\sigma_{v}: \mathbf{X} \rightarrow[0,1]$ is the voting function. As above, $U: \mathbf{X} \rightarrow \mathbb{R}$ denotes the players' utility function. ${ }^{4}$ Define $\tilde{u} \in \mathbb{R}$ as the disagreement utility under $\left(\sigma_{p}, \sigma_{v}\right)$, i.e. the expected utility in case the next proposal is not accepted, and initially let us take it as given. The logit voting function $\sigma_{v}$ solves $^{5}$

$$
\sigma_{v}\left(\mathbf{x}^{1} \mid \tilde{u}\right)=\frac{\exp \left\{\lambda^{v} \cdot U\left(\mathbf{x}^{1}\right)\right\}}{\exp \left\{\lambda^{v} \cdot U\left(\mathbf{x}^{1}\right)\right\}+\exp \left\{\lambda^{v}\left(\sigma_{v}\left(\mathbf{x}^{2} \mid \tilde{u}\right) * U\left(\mathbf{x}^{1}\right)+\left(1-\sigma_{v}\left(\mathbf{x}^{2} \mid \tilde{u}\right)\right) * \tilde{u}\right)\right\}} .
$$

The corresponding probability that $\mathbf{x}$ will be accepted, conditional on $\tilde{u}$ and $\sigma_{v}$, is

$$
\operatorname{Pr}(\mathbf{x})=1-\left[1-\sigma_{v}\left(\mathbf{x}^{1} \mid \tilde{u}\right)\right]\left[1-\sigma_{v}\left(\mathbf{x}^{2} \mid \tilde{u}\right)\right] .
$$

and thus the expected utility of the proposer from proposing $\mathbf{x} \in \mathbf{X}$ is

$$
v_{i}(\mathbf{x})=\operatorname{Pr}(\mathbf{x}) \cdot u_{i}(\mathbf{x})+(1-\operatorname{Pr}(\mathbf{x})) \cdot \tilde{u} .
$$

Given $v_{i}$, the proposal function $\sigma_{p}$ is defined by Eq. (12). We allow for heterogenous precision parameters $\lambda^{p}$ and $\lambda^{v}$ for proposers and voters, respectively,

\footnotetext{
${ }^{3}$ McFadden (1984, p. 1422ff) provides the distribution of the random utility component that gives rise to this three-level nested logit model.

${ }^{4}$ Also as above, the argument of $U(\mathbf{x})$, i.e. $\mathbf{x}=\left(x_{1}, x_{2}, x_{3}\right)$, is understood to have the payoff of the respective player as $x_{1}$, and the opponents' payoffs as $x_{2}$ and $x_{3}$. We assume $U\left(x_{1}, x_{2}, x_{3}\right)=$ $U\left(x_{1}, x_{3}, x_{2}\right)$.

${ }^{5}$ The following expression uses a notation of permutations of $\mathbf{x} \in \mathbf{X}$. In general, $\mathbf{x}$ is in the order $\left(x_{p}, x_{1}, x_{2}\right)$, i.e. the first value refers to the proposer, the second value to the first voter, and the third value to the second voter. We define $\mathbf{x}^{1}:=\left(x_{1}, x_{p}, x_{2}\right)$ and $\mathbf{x}^{2}:=\left(x_{2}, x_{p}, x_{1}\right)$.
} 
because their choice problems have different complexity (following e.g. Rogers et al., 2009). Finally, let $\mathbf{u} \in \mathbb{R}^{N}$ denote the expected payoff of all $i \in N$ under $\left(\sigma_{p}, \sigma_{v}\right)$, and define

$$
\bar{u}=\delta \cdot\left(u_{1}+u_{2}+u_{3}\right) / 3+(1-\delta) \cdot U(0,0,0) .
$$

In any stationary QRE of $P B 95, \tilde{u}=\bar{u}$. We determine the equilibrium $\left(\sigma_{p}, \sigma_{v}\right)$ by function iteration using the starting value $\tilde{u}=U(7,7,7)$. The stationary equilibrium is unique if and only if the voting equilibria (13) are unique for all proposals $\mathbf{x} \in \mathbf{X}$, but conditions for the latter do not seem available. In our computations, the function iteration generally converged quickly to the fixed point $(\tilde{u}=\bar{u})$, which suggests that the equilibrium is stable and locally unique. ${ }^{6}$

The strategy profile $\left(\sigma_{p}, \sigma_{v}\right)$ is the symmetric QRE of $P B O 0$ for $\tilde{u}=U(7.6,7.6,7.6)$.

\section{References}

McFadden, D. (1978). Modelling the choice of residential location. In Karlqvist, A., Lundqvist, L., Snickars, F., and Weibull, J., editors, Spatial interaction theory and planning models, pages 75-96. North Holland, Amsterdam.

McFadden, D. (1984). Econometric analysis of qualitative response models. Handbook of econometrics, 2:1395-1457.

Rogers, B., Palfrey, T., and Camerer, C. (2009). Heterogeneous quantal response equilibrium and cognitive hierarchies. Journal of Economic Theory, 144(4):14401467.

\footnotetext{
${ }^{6}$ For each proposal $\mathbf{x} \in \mathbf{X}$, the equilibrium acceptance probabilities $\sigma_{1}(\mathbf{x})$ and $\sigma_{2}(\mathbf{x})$ of the voters had also been determined by function iteration, using the starting probabilities $(0.5,0.5)$. In this case, the function iteration was dampened to ensure robust convergence. the smallest currency unit used in the structural analysis is $€ 0.2$ (most actual proposals had been multiples of it, and the remaining few had been rounded appropriately).
} 


\section{Overview model fit (BIC)}

The following tables complement those of the paper by providing the BIC measures for goodness-of-fit.

Table 1: Goodness of fits of logit and nested logit models

\begin{tabular}{lcccc}
\hline \hline & & \multicolumn{3}{c}{ Number of types } \\
\cline { 3 - 5 } & Logit Eq. & One & Two & Three \\
\hline CES & 4513 & 3993 & 3869 & 3672 \\
Ineq & 4571 & 3836 & 3685 & 3640 \\
RRDA & 4132 & 3668 & 3454 & 3464 \\
ARDA & 4344 & 3622 & 3469 & 3481 \\
\hline \hline
\end{tabular}

Table 2: Goodness of fits of mixed multi-type models

\begin{tabular}{lcccc}
\hline \hline & \multicolumn{4}{c}{ Added type } \\
\cline { 2 - 5 } & CES & IneqAv & RRDA & ARDA \\
\hline CES + & 3869 & 3719 & 3574 & 3593 \\
IneqAv + & 3719 & 3685 & 3520 & 3510 \\
RRDA + & 3574 & 3520 & 3454 & 3396 \\
ARDA + & 3593 & 3510 & 3396 & 3469 \\
\hline CES + IneqAv + & 3711 & 3715 & 3488 & 3509 \\
CES + RRDA + & 3475 & 3487 & 3493 & 3396 \\
IneqAv + ARDA + & 3509 & 3496 & 3382 & 3501 \\
RRDA + ARDA + & 3396 & 3383 & 3387 & 3402 \\
\hline \hline
\end{tabular}

Table 3: Goodness of fits of heterogenous models

\begin{tabular}{lcccc}
\hline \hline & \multicolumn{4}{c}{ Voter type } \\
\cline { 2 - 5 } Proposer & CES & IneqAv & RRDA & ARDA \\
\hline CES + & 3996 & 3936 & 4164 & 4099 \\
IneqAv + & 3741 & 3839 & 3709 & 3547 \\
RRDA + & 3748 & 3835 & 3650 & 3605 \\
ARDA + & 3756 & 3910 & 3784 & 3597 \\
\hline \hline
\end{tabular}




\section{Parameter estimates}

The notation of the RDA utility functions is slightly different than in the paper. Here, they are defined as follows.

$$
\begin{aligned}
& U_{i}^{A R D A}(\mathbf{x})=x_{i}+\alpha \sum_{j \neq i} x_{j} \cdot I_{x_{i} \geq x_{i}^{*}}+\beta \sum_{j \neq i} x_{j} \cdot I_{x_{j}<x_{i}^{*}} \\
& U_{i}^{R R D A}(\mathbf{x})=x_{i}-\alpha \sum_{j \neq i} x_{j} \cdot I_{x_{i}<x_{j}}-\beta \sum_{j \neq i} x_{j} \cdot I_{x_{i} \geq x_{j}},
\end{aligned}
$$

Table 4: Parameter estimates for logit and nested logit models without mixture of motives

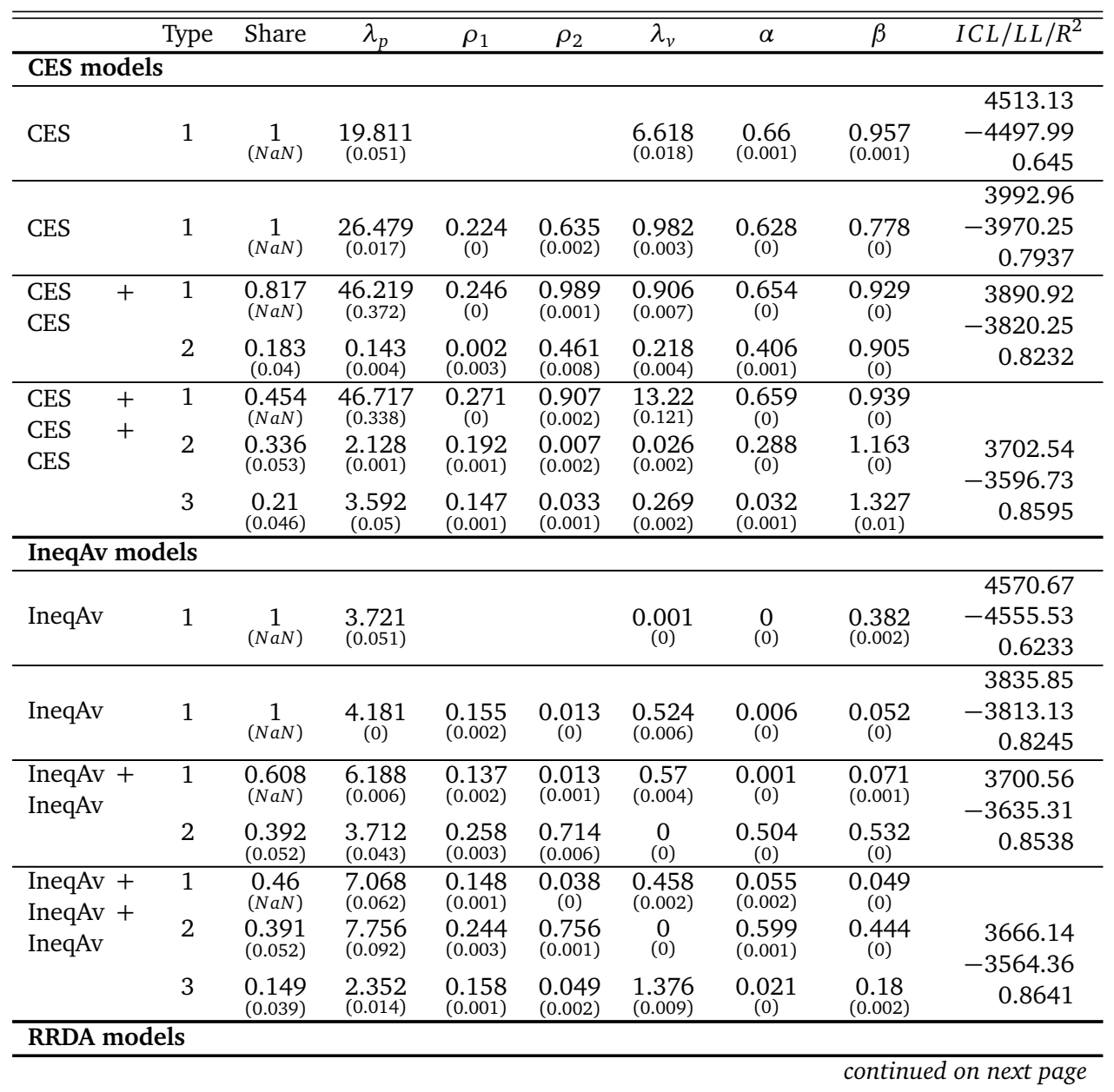




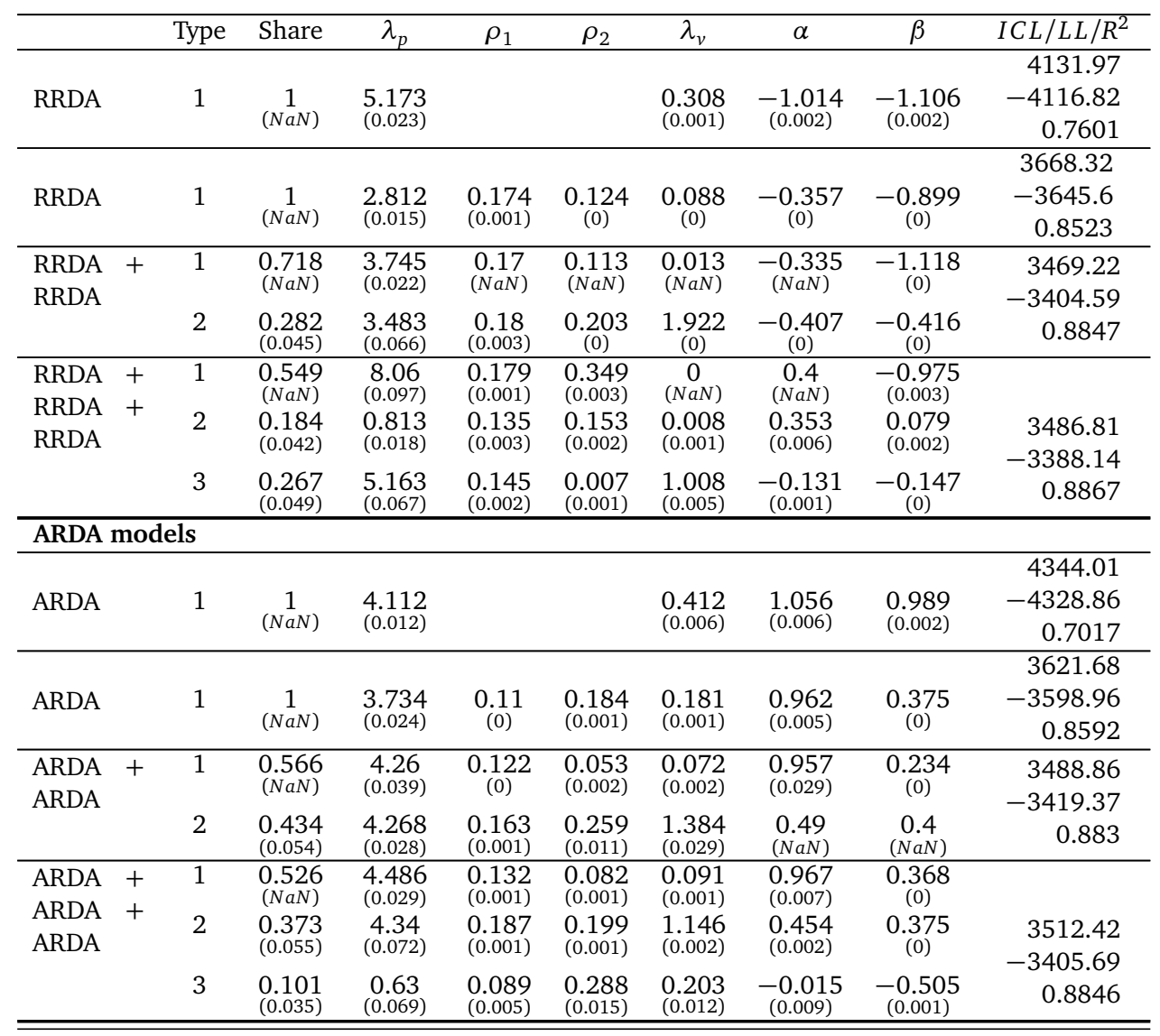

Table 5: Two-type mixed models

\begin{tabular}{|c|c|c|c|c|c|c|c|c|c|}
\hline & Type & Share & $\overline{\lambda_{p}}$ & $\rho_{1}$ & $\overline{\rho \rho_{2}}$ & $\overline{\lambda_{v}}$ & $\bar{\alpha}$ & $\bar{\beta}$ & $\overline{I C L / L L / R^{2}}$ \\
\hline \multicolumn{10}{|l|}{ CES $+\ldots$} \\
\hline \multirow[t]{2}{*}{$\begin{array}{l}\text { CES } \\
\text { CES }\end{array}$} & 1 & $\begin{array}{l}0.817 \\
(\mathrm{NaN})\end{array}$ & $\begin{array}{c}46.219 \\
(0.05)\end{array}$ & $\begin{array}{l}0.246 \\
(0.001)\end{array}$ & $\begin{array}{l}0.989 \\
(0.003)\end{array}$ & $\begin{array}{l}0.906 \\
(0.002)\end{array}$ & $\begin{array}{c}0.654 \\
(0)\end{array}$ & $\begin{array}{c}0.929 \\
(0)\end{array}$ & \multirow{2}{*}{$\begin{array}{r}3890.93 \\
-3820.27 \\
0.8232\end{array}$} \\
\hline & 2 & $\begin{array}{l}0.183 \\
(0.04)\end{array}$ & $\begin{array}{l}0.143 \\
(0.003)\end{array}$ & $\begin{array}{l}0.002 \\
(0.001)\end{array}$ & $\begin{array}{l}0.461 \\
(0.019)\end{array}$ & $\begin{array}{l}0.218 \\
(0.005)\end{array}$ & $\underset{(0)}{0.406}$ & $\begin{array}{c}0.905 \\
(0)\end{array}$ & \\
\hline \multirow[t]{2}{*}{$\begin{array}{l}\text { CES + In- } \\
\text { eqAv }\end{array}$} & 1 & $\begin{array}{l}0.326 \\
(\mathrm{NaN})\end{array}$ & $\begin{array}{c}29.01 \\
(0.06)\end{array}$ & $\begin{array}{c}0.356 \\
(0)\end{array}$ & $\begin{array}{l}0.634 \\
(0.001)\end{array}$ & $\begin{array}{c}5.34 \\
(0.037)\end{array}$ & $\begin{array}{l}0.654 \\
(0.001)\end{array}$ & $\begin{array}{l}0.776 \\
(0.001)\end{array}$ & \multirow{2}{*}{$\begin{array}{r}3730.59 \\
-3669.38 \\
0.8486\end{array}$} \\
\hline & 2 & $\begin{array}{l}0.674 \\
(0.049)\end{array}$ & $\begin{array}{l}5.974 \\
(0.019) \\
\end{array}$ & $\begin{array}{c}0.153 \\
(0)\end{array}$ & $\begin{array}{c}0.002 \\
(0)\end{array}$ & $\begin{array}{c}0.435 \\
(0)\end{array}$ & $\underset{(0)}{0.015}$ & $\begin{array}{c}0.066 \\
(0)\end{array}$ & \\
\hline \multirow[t]{2}{*}{$\begin{array}{l}\text { CES } \\
\text { RRDA }\end{array}$} & 1 & $\begin{array}{l}0.318 \\
(\mathrm{NaN})\end{array}$ & $\begin{array}{c}28.578 \\
(0.024)\end{array}$ & $\begin{array}{l}0.291 \\
(0.001)\end{array}$ & $\begin{array}{l}0.675 \\
(0.004)\end{array}$ & $\begin{array}{l}8.953 \\
(0.111)\end{array}$ & $\begin{array}{c}0.655 \\
(0)\end{array}$ & $\underset{(0)}{0.86}$ & \multirow{2}{*}{$\begin{array}{r}3591.86 \\
-3524.56 \\
0.8696 \\
\end{array}$} \\
\hline & 2 & $\begin{array}{l}0.682 \\
(0.054)\end{array}$ & $\begin{array}{r}4.189 \\
(0.051) \\
\end{array}$ & $\begin{array}{l}0.168 \\
(0.001)\end{array}$ & $\begin{array}{l}0.118 \\
(0.001)\end{array}$ & $\begin{array}{l}0.065 \\
(0.002)\end{array}$ & $\begin{array}{c}-0.327 \\
(\mathrm{NaN})\end{array}$ & $\begin{array}{c}-0.679 \\
(0.005)\end{array}$ & \\
\hline $\begin{array}{l}\text { CES }+ \\
\text { ARPA }\end{array}$ & 1 & $\begin{array}{l}0.134 \\
(\mathrm{NaN})\end{array}$ & $\begin{array}{l}27.74 \\
(0.174) \\
\end{array}$ & $\begin{array}{l}0.251 \\
(0.001) \\
\end{array}$ & $\begin{array}{c}0.631 \\
(0)\end{array}$ & $\begin{array}{l}4.852 \\
(0.013) \\
\end{array}$ & $\begin{array}{c}0.643 \\
(0)\end{array}$ & $\begin{array}{l}0.727 \\
(0.002) \\
\end{array}$ & \\
\hline
\end{tabular}




\begin{tabular}{|c|c|c|c|c|c|c|c|c|c|}
\hline & Type & Share & $\lambda_{p}$ & $\rho_{1}$ & $\rho_{2}$ & $\lambda_{v}$ & $\alpha$ & $\beta$ & 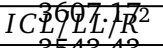 \\
\hline & 2 & $\begin{array}{l}0.866 \\
(0.034)\end{array}$ & $\begin{array}{l}3.502 \\
(0.021)\end{array}$ & $\begin{array}{c}0.16 \\
(0.001)\end{array}$ & $\underset{(0)}{0.112}$ & $\begin{array}{c}0.173 \\
(0)\end{array}$ & $\begin{array}{l}0.885 \\
(0.004)\end{array}$ & $\begin{array}{c}0.368 \\
(0)\end{array}$ & 0.867 \\
\hline \multicolumn{10}{|c|}{ IneqAv $+\ldots$} \\
\hline \multirow[t]{2}{*}{$\begin{array}{l}\text { IneqAv + } \\
\text { CES }\end{array}$} & 1 & $\begin{array}{l}0.675 \\
(N a N)\end{array}$ & $\begin{array}{l}6.124 \\
(0.203)\end{array}$ & $\begin{array}{l}0.149 \\
(0.005)\end{array}$ & $\begin{array}{l}0.003 \\
(0.004)\end{array}$ & $\begin{array}{l}0.433 \\
(0.006)\end{array}$ & $\begin{array}{c}0.015 \\
(0)\end{array}$ & $\begin{array}{c}0.065 \\
(0)\end{array}$ & \multirow{2}{*}{$\begin{array}{r}3730.81 \\
-3669.48 \\
0.8486\end{array}$} \\
\hline & 2 & $\begin{array}{l}0.325 \\
(0.049) \\
\end{array}$ & $\begin{array}{c}32.592 \\
(0.034)\end{array}$ & $\begin{array}{l}0.357 \\
(0.001) \\
\end{array}$ & $\begin{array}{l}0.633 \\
(0.003) \\
\end{array}$ & $\begin{array}{l}4.495 \\
(0.053) \\
\end{array}$ & $\begin{array}{c}0.654 \\
(0)\end{array}$ & $\begin{array}{c}0.779 \\
(0)\end{array}$ & \\
\hline \multirow[t]{2}{*}{$\begin{array}{l}\text { IneqAv + } \\
\text { IneqAv }\end{array}$} & 1 & $\begin{array}{l}0.602 \\
(N a N)\end{array}$ & $\begin{array}{l}6.163 \\
(0.007)\end{array}$ & $\begin{array}{c}0.136 \\
(0)\end{array}$ & $\begin{array}{c}0.02 \\
(0)\end{array}$ & $\begin{array}{l}0.569 \\
(0.002)\end{array}$ & $\begin{array}{c}0.003 \\
(0)\end{array}$ & $\begin{array}{c}0.071 \\
(0)\end{array}$ & \multirow{2}{*}{$\begin{array}{r}3701.2 \\
-3635.59 \\
0.8538\end{array}$} \\
\hline & 2 & $\begin{array}{l}0.398 \\
(0.052)\end{array}$ & $\begin{array}{c}3.712 \\
(0)\end{array}$ & $\begin{array}{c}0.239 \\
(0)\end{array}$ & $\begin{array}{c}0.691 \\
(0.01)\end{array}$ & $\begin{array}{c}0 \\
(0)\end{array}$ & $\begin{array}{l}0.511 \\
(0.007)\end{array}$ & $\begin{array}{c}0.541 \\
(0)\end{array}$ & \\
\hline \multirow[t]{2}{*}{$\begin{array}{l}\text { IneqAv + } \\
\text { RRDA }\end{array}$} & 1 & $\begin{array}{l}0.258 \\
(\mathrm{NaN})\end{array}$ & $\begin{array}{l}2.596 \\
(0.086)\end{array}$ & $\begin{array}{l}0.188 \\
(0.004)\end{array}$ & $\begin{array}{l}0.096 \\
(\mathrm{NaN})\end{array}$ & $\begin{array}{l}2.445 \\
(0.034)\end{array}$ & $\begin{array}{l}0.011 \\
(\mathrm{NaN})\end{array}$ & $\begin{array}{l}0.046 \\
(\mathrm{NaN})\end{array}$ & \multirow{2}{*}{$\begin{array}{r}3534.5 \\
-3470.35 \\
0.8767\end{array}$} \\
\hline & 2 & $\begin{array}{l}0.742 \\
(0.047) \\
\end{array}$ & $\begin{array}{l}5.928 \\
(0.072) \\
\end{array}$ & $\begin{array}{l}0.133 \\
(0.004)\end{array}$ & $\begin{array}{l}0.097 \\
(0.001)\end{array}$ & $\begin{array}{c}0 \\
(0)\end{array}$ & $\begin{array}{c}-0.438 \\
(0.003)\end{array}$ & $\begin{array}{c}-1.141 \\
(0.011)\end{array}$ & \\
\hline \multirow[t]{2}{*}{$\begin{array}{l}\text { IneqAv + } \\
\text { ARDA }\end{array}$} & 1 & $\begin{array}{c}0.34 \\
(\mathrm{NaN})\end{array}$ & $\begin{array}{l}8.373 \\
(0.019)\end{array}$ & $\begin{array}{l}0.131 \\
(0.001)\end{array}$ & $\begin{array}{c}0.008 \\
(0)\end{array}$ & $\begin{array}{l}0.466 \\
(0.003)\end{array}$ & $\begin{array}{c}0.023 \\
(0)\end{array}$ & $\begin{array}{c}0.071 \\
(0)\end{array}$ & \multirow{2}{*}{$\begin{array}{r}3524.85 \\
-3460.97 \\
0.8778\end{array}$} \\
\hline & 2 & $\begin{array}{l}0.66 \\
(0.05) \\
\end{array}$ & $\begin{array}{l}2.547 \\
(0.012) \\
\end{array}$ & $\begin{array}{l}0.122 \\
(0.001) \\
\end{array}$ & $\begin{array}{l}0.005 \\
(0.001) \\
\end{array}$ & $\begin{array}{l}0.168 \\
(0.001) \\
\end{array}$ & $\begin{array}{l}1.102 \\
(0.009) \\
\end{array}$ & $\begin{array}{c}0.337 \\
(0)\end{array}$ & \\
\hline \multicolumn{10}{|c|}{ RRDA + ... } \\
\hline \multirow[t]{2}{*}{$\begin{array}{l}\text { RRDA + } \\
\text { CES }\end{array}$} & 1 & $\begin{array}{l}0.693 \\
(\text { NaN })\end{array}$ & $\begin{array}{l}4.121 \\
(0.02)\end{array}$ & $\begin{array}{l}0.175 \\
(\mathrm{NaN})\end{array}$ & $\begin{array}{c}0.12 \\
(0.001)\end{array}$ & $\begin{array}{l}0.062 \\
(\mathrm{NaN})\end{array}$ & $\begin{array}{c}-0.325 \\
(\mathrm{NaN})\end{array}$ & $\begin{array}{c}-0.678 \\
(0.003)\end{array}$ & \multirow{2}{*}{$\begin{array}{r}3591.48 \\
-3524.66 \\
0.8696\end{array}$} \\
\hline & 2 & $\begin{array}{l}0.307 \\
(0.052) \\
\end{array}$ & $\begin{array}{c}28.717 \\
(0.298) \\
\end{array}$ & $\begin{array}{l}0.281 \\
(0.001) \\
\end{array}$ & $\begin{array}{l}0.684 \\
(0.001) \\
\end{array}$ & $\begin{array}{c}8.95 \\
(0.072) \\
\end{array}$ & $\begin{array}{c}0.641 \\
(0)\end{array}$ & $\begin{array}{c}0.87 \\
(0)\end{array}$ & \\
\hline \multirow[t]{2}{*}{$\begin{array}{l}\text { RRDA + } \\
\text { IneqAv }\end{array}$} & 1 & $\begin{array}{l}0.746 \\
(\mathrm{NaN})\end{array}$ & $\begin{array}{l}5.878 \\
(0.014)\end{array}$ & $\begin{array}{l}0.133 \\
(0.001)\end{array}$ & $\begin{array}{l}0.097 \\
(0.001)\end{array}$ & $\begin{array}{c}0 \\
(0)\end{array}$ & $\begin{array}{c}-0.422 \\
(0.003)\end{array}$ & $\begin{array}{c}-1.115 \\
(0.001)\end{array}$ & \multirow{2}{*}{$\begin{array}{r}3534.87 \\
-3470.54 \\
0.8766\end{array}$} \\
\hline & 2 & $\begin{array}{l}0.254 \\
(0.047) \\
\end{array}$ & $\begin{array}{c}2.579 \\
(0)\end{array}$ & $\begin{array}{c}0.188 \\
(0)\end{array}$ & $\begin{array}{l}0.097 \\
(0.001)\end{array}$ & $\begin{array}{l}2.444 \\
(0.071) \\
\end{array}$ & $\begin{array}{l}0.012 \\
(0.001) \\
\end{array}$ & $\begin{array}{l}0.046 \\
(0.001) \\
\end{array}$ & \\
\hline \multirow[t]{2}{*}{$\begin{array}{ll}\text { RRDA }+ \\
\text { RRDA }\end{array}$} & 1 & $\begin{array}{l}0.718 \\
(\mathrm{NaN})\end{array}$ & $\begin{array}{l}3.745 \\
(0.032)\end{array}$ & $\begin{array}{c}0.17 \\
(\mathrm{NaN})\end{array}$ & $\begin{array}{l}0.113 \\
(\mathrm{NaN})\end{array}$ & $\begin{array}{l}0.013 \\
(\mathrm{NaN})\end{array}$ & $\begin{array}{c}-0.335 \\
(\mathrm{NaN})\end{array}$ & -1.118 & \multirow{2}{*}{$\begin{array}{r}3469.22 \\
-3404.59 \\
0.8847\end{array}$} \\
\hline & 2 & $\begin{array}{l}0.282 \\
(0.045)\end{array}$ & $\begin{array}{l}3.483 \\
(0.039)\end{array}$ & $\begin{array}{c}0.18 \\
(0.002)\end{array}$ & $\begin{array}{c}0.203 \\
(0)\end{array}$ & $\begin{array}{c}1.922 \\
(0)\end{array}$ & $\begin{array}{c}-0.407 \\
(0)\end{array}$ & $\begin{array}{c}-0.416 \\
(0)\end{array}$ & \\
\hline \multirow[t]{2}{*}{$\begin{array}{l}\text { RRDA } \\
\text { ARDA }\end{array}$} & 1 & $\begin{array}{l}0.552 \\
(\mathrm{NaN})\end{array}$ & $\begin{array}{l}5.542 \\
(0.093)\end{array}$ & $\begin{array}{l}0.145 \\
(0.004)\end{array}$ & $\begin{array}{l}0.101 \\
(0.001)\end{array}$ & $\begin{array}{l}0.001 \\
(0.002)\end{array}$ & $\begin{array}{l}-0.27 \\
(0.002)\end{array}$ & $\begin{array}{c}-0.998 \\
(0.007)\end{array}$ & \multirow{2}{*}{$\begin{array}{r}3415.11 \\
-3346.74 \\
0.8914\end{array}$} \\
\hline & 2 & $\begin{array}{l}0.448 \\
(0.054) \\
\end{array}$ & $\begin{array}{l}3.332 \\
(0.042) \\
\end{array}$ & $\begin{array}{c}0.119 \\
(0)\end{array}$ & $\begin{array}{c}0.088 \\
(0)\end{array}$ & $\begin{array}{l}0.317 \\
(0.002) \\
\end{array}$ & $\begin{array}{l}0.795 \\
(0.006) \\
\end{array}$ & $\begin{array}{c}0.334 \\
(0)\end{array}$ & \\
\hline \multicolumn{10}{|c|}{ ARDA + ... } \\
\hline \multirow[t]{2}{*}{$\begin{array}{l}\text { ARDA + } \\
\text { CES }\end{array}$} & 1 & $\begin{array}{l}0.866 \\
(N a N)\end{array}$ & $\begin{array}{l}3.501 \\
(0.003)\end{array}$ & $\begin{array}{c}0.16 \\
(0)\end{array}$ & $\begin{array}{c}0.111 \\
(0)\end{array}$ & $\begin{array}{c}0.173 \\
(0)\end{array}$ & $\begin{array}{l}0.885 \\
(0.001)\end{array}$ & $\begin{array}{c}0.367 \\
(0)\end{array}$ & \multirow{2}{*}{$\begin{array}{r}3607.18 \\
-3543.45 \\
0.867\end{array}$} \\
\hline & 2 & $\begin{array}{l}0.134 \\
(0.034) \\
\end{array}$ & $\begin{array}{c}27.741 \\
(0.089) \\
\end{array}$ & $\begin{array}{l}0.251 \\
(0.001) \\
\end{array}$ & $\begin{array}{l}0.631 \\
(0.003) \\
\end{array}$ & $\begin{array}{l}4.852 \\
(0.053) \\
\end{array}$ & $\begin{array}{c}0.643 \\
(0)\end{array}$ & $\begin{array}{l}0.727 \\
(0.001) \\
\end{array}$ & \\
\hline \multirow[t]{2}{*}{$\begin{array}{l}\text { ARDA }+ \\
\text { IneqAv }\end{array}$} & 1 & $\begin{array}{c}0.66 \\
(\mathrm{NaN})\end{array}$ & $\begin{array}{l}2.546 \\
(0.055)\end{array}$ & $\begin{array}{l}0.122 \\
(0.001)\end{array}$ & $\begin{array}{l}0.011 \\
(0.001)\end{array}$ & $\begin{array}{l}0.168 \\
(0.001)\end{array}$ & $\begin{array}{l}1.101 \\
(0.058)\end{array}$ & $\begin{array}{c}0.334 \\
(0)\end{array}$ & \multirow{2}{*}{$\begin{array}{r}3524.8 \\
-3461.07 \\
0.8778\end{array}$} \\
\hline & 2 & $\begin{array}{l}0.34 \\
(0.05) \\
\end{array}$ & $\begin{array}{c}8.34 \\
(0.329)\end{array}$ & $\begin{array}{l}0.133 \\
(0.002)\end{array}$ & $\begin{array}{l}0.007 \\
(0.004)\end{array}$ & $\begin{array}{l}0.466 \\
(0.019)\end{array}$ & $\begin{array}{l}0.026 \\
(0.003)\end{array}$ & $\begin{array}{l}0.069 \\
(0.005)\end{array}$ & \\
\hline \multirow[t]{2}{*}{$\begin{array}{l}\text { ARDA } \\
\text { RRDA }\end{array}$} & 1 & $\begin{array}{l}0.448 \\
(\mathrm{NaN})\end{array}$ & $\begin{array}{l}3.332 \\
(0.042)\end{array}$ & $\begin{array}{c}0.119 \\
(0)\end{array}$ & $\begin{array}{c}0.088 \\
(0)\end{array}$ & $\begin{array}{l}0.317 \\
(0.002)\end{array}$ & $\begin{array}{l}0.795 \\
(0.006)\end{array}$ & $\begin{array}{c}0.334 \\
(0)\end{array}$ & \multirow{2}{*}{$\begin{array}{r}3415.11 \\
-3346.74 \\
0.8914\end{array}$} \\
\hline & 2 & $\begin{array}{l}0.552 \\
(0.054) \\
\end{array}$ & $\begin{array}{l}5.542 \\
(0.093) \\
\end{array}$ & $\begin{array}{l}0.145 \\
(0.004)\end{array}$ & $\begin{array}{l}0.101 \\
(0.001)\end{array}$ & $\begin{array}{l}0.001 \\
(0.002) \\
\end{array}$ & $\begin{array}{l}-0.27 \\
(0.002)\end{array}$ & $\begin{array}{c}-0.998 \\
(0.007)\end{array}$ & \\
\hline \multirow[t]{2}{*}{$\begin{array}{l}\text { ARDA } \\
\text { ARDA }\end{array}$} & 1 & $\begin{array}{l}0.566 \\
(\mathrm{NaN})\end{array}$ & $\begin{array}{c}4.26 \\
(0.025)\end{array}$ & $\begin{array}{l}0.122 \\
(0.002)\end{array}$ & $\begin{array}{l}0.053 \\
(0.001)\end{array}$ & $\begin{array}{c}0.072 \\
(0)\end{array}$ & $\begin{array}{l}0.957 \\
(0.004)\end{array}$ & $\begin{array}{c}0.234 \\
(0)\end{array}$ & \multirow{2}{*}{$\begin{array}{r}3488.85 \\
-3419.37 \\
0.883\end{array}$} \\
\hline & 2 & $\begin{array}{l}0.434 \\
(0.054) \\
\end{array}$ & $\begin{array}{l}4.268 \\
(0.017) \\
\end{array}$ & $\begin{array}{l}0.163 \\
(0.001) \\
\end{array}$ & $\begin{array}{l}0.259 \\
(0.001) \\
\end{array}$ & $\begin{array}{l}1.384 \\
(0.008) \\
\end{array}$ & $\begin{array}{c}0.49 \\
(N a N)\end{array}$ & $\begin{array}{c}0.4 \\
(\mathrm{NaN})\end{array}$ & \\
\hline
\end{tabular}


Table 6: Three-type mixed models

\begin{tabular}{|c|c|c|c|c|c|c|c|c|c|c|}
\hline & & Type & Share & $\lambda_{p}$ & $\rho_{1}$ & $\rho_{2}$ & $\lambda_{v}$ & $\alpha$ & $\bar{\beta}$ & $\overline{I C L / L L / R^{2}}$ \\
\hline \multicolumn{11}{|c|}{ CES + Inequity Aversion $+\ldots$} \\
\hline \multirow{3}{*}{\multicolumn{2}{|c|}{$\begin{array}{l}\text { CES + } \\
\text { IneqAv + } \\
\text { CES }\end{array}$}} & 1 & $\begin{array}{l}0.124 \\
(\text { NaN })\end{array}$ & $\begin{array}{c}29.019 \\
(0.063)\end{array}$ & $\begin{array}{l}0.353 \\
(0.003)\end{array}$ & $\begin{array}{l}0.638 \\
(0.002)\end{array}$ & $\begin{array}{l}7.398 \\
(0.037)\end{array}$ & $\begin{array}{c}0.657 \\
(0)\end{array}$ & $\begin{array}{c}0.916 \\
(0)\end{array}$ & \\
\hline & & 2 & $\begin{array}{l}0.678 \\
(0.056)\end{array}$ & $\begin{array}{l}5.922 \\
(0.045)\end{array}$ & $\begin{array}{l}0.156 \\
(0.001)\end{array}$ & $\begin{array}{l}0.003 \\
(0.001)\end{array}$ & $\begin{array}{l}0.431 \\
(0.005)\end{array}$ & $\begin{array}{l}0.014 \\
(0.001)\end{array}$ & $\begin{array}{c}0.064 \\
(0)\end{array}$ & $\begin{array}{r}3744.59 \\
-3635.41\end{array}$ \\
\hline & & 3 & $\begin{array}{l}0.198 \\
(0.058)\end{array}$ & $\begin{array}{c}20.875 \\
(0.085) \\
\end{array}$ & $\begin{array}{l}0.318 \\
(0.001)\end{array}$ & $\begin{array}{l}0.644 \\
(0.002)\end{array}$ & $\begin{array}{l}0.958 \\
(0.007) \\
\end{array}$ & $\begin{array}{c}0.628 \\
(0)\end{array}$ & $\begin{array}{c}0.735 \\
(0)\end{array}$ & 0.8538 \\
\hline \multirow{3}{*}{$\begin{array}{l}\text { CES } \\
\text { IneqAv } \\
\text { IneqAv }\end{array}$} & & 1 & $\begin{array}{l}0.171 \\
(\text { NaN })\end{array}$ & $\begin{array}{l}41.84 \\
(0.105)\end{array}$ & $\underset{(0)}{0.364}$ & $\begin{array}{l}0.632 \\
(0.001)\end{array}$ & $\begin{array}{l}5.421 \\
(0.059)\end{array}$ & $\begin{array}{c}0.65 \\
(0)\end{array}$ & $\begin{array}{l}0.805 \\
(0)\end{array}$ & \\
\hline & & 2 & $\begin{array}{l}0.637 \\
(0.055)\end{array}$ & $\begin{array}{l}7.079 \\
(0.082)\end{array}$ & 0.153 & $\begin{array}{l}0.005 \\
(0.001)\end{array}$ & $\begin{array}{l}0.439 \\
(0.005)\end{array}$ & $\begin{array}{l}0.016 \\
(0.001)\end{array}$ & $\begin{array}{l}0.067 \\
(0.001)\end{array}$ & $\begin{array}{r}3750.76 \\
-363968\end{array}$ \\
\hline & & 3 & $\begin{array}{l}0.192 \\
(0.053) \\
\end{array}$ & $\begin{array}{l}3.111 \\
(0.098) \\
\end{array}$ & $\begin{array}{l}0.153 \\
(0.003) \\
\end{array}$ & $\begin{array}{l}0.032 \\
(0.003) \\
\end{array}$ & $\begin{array}{l}0.521 \\
(0.013) \\
\end{array}$ & $\begin{array}{c}0 \\
(0.002) \\
\end{array}$ & $\begin{array}{l}0.198 \\
(0.007) \\
\end{array}$ & 0.8532 \\
\hline \multirow{3}{*}{$\begin{array}{l}\text { CES } \\
\text { IneqAv } \\
\text { RRDA }\end{array}$} & & 1 & $\begin{array}{l}0.146 \\
(\mathrm{NaN})\end{array}$ & $\begin{array}{c}28.331 \\
(0.068)\end{array}$ & $\begin{array}{c}0.304 \\
(0)\end{array}$ & $\underset{(0)}{0.679}$ & $\begin{array}{l}9.137 \\
(0.004)\end{array}$ & $\begin{array}{c}0.667 \\
(0)\end{array}$ & $\begin{array}{c}0.884 \\
(0)\end{array}$ & \\
\hline & & 2 & $\begin{array}{l}0.195 \\
(0.04)\end{array}$ & $\begin{array}{l}4.176 \\
(0.003)\end{array}$ & $\begin{array}{l}0.272 \\
(0.002)\end{array}$ & $\begin{array}{l}0.035 \\
(0.001)\end{array}$ & $\begin{array}{l}0.541 \\
(0.001)\end{array}$ & $\begin{array}{c}0.034 \\
(0)\end{array}$ & $\begin{array}{c}0.044 \\
(0)\end{array}$ & $\begin{array}{r}3513.83 \\
-341181\end{array}$ \\
\hline & & 3 & $\begin{array}{c}0.659 \\
(0.05)\end{array}$ & $\begin{array}{c}4.24 \\
(0.068) \\
\end{array}$ & $\begin{array}{c}0.198 \\
(0)\end{array}$ & $\begin{array}{l}0.101 \\
(0.001)\end{array}$ & $\begin{array}{l}0.039 \\
(0.001) \\
\end{array}$ & $\begin{array}{c}-0.322 \\
(0.003)\end{array}$ & $\begin{array}{c}-1.019 \\
(0.001)\end{array}$ & 0.8839 \\
\hline \multirow{3}{*}{$\begin{array}{l}\text { CES } \\
\text { IneqAv } \\
\text { ARDA }\end{array}$} & + & 1 & $\begin{array}{l}0.064 \\
(\mathrm{NaN})\end{array}$ & $\begin{array}{c}20.263 \\
(0.006)\end{array}$ & $\underset{(0)}{0.24}$ & $\underset{(0)}{0.635}$ & $\begin{array}{l}2.465 \\
(0.001)\end{array}$ & $\begin{array}{c}0.667 \\
(0)\end{array}$ & $\underset{(0)}{0.874}$ & \\
\hline & + & 2 & $\begin{array}{l}0.309 \\
(0.048)\end{array}$ & $\begin{array}{l}8.874 \\
(0.026)\end{array}$ & $\begin{array}{l}0.127 \\
(0.001)\end{array}$ & $\begin{array}{l}0.006 \\
(0.001)\end{array}$ & $\begin{array}{l}0.456 \\
(0.002)\end{array}$ & $\begin{array}{c}0.02 \\
(0.001)\end{array}$ & $\begin{array}{l}0.071 \\
(0.001)\end{array}$ & $\begin{array}{r}3533.83 \\
-3432.93\end{array}$ \\
\hline & & 3 & $\begin{array}{r}0.627 \\
(0.051) \\
\end{array}$ & $\begin{array}{l}2.589 \\
(0.002) \\
\end{array}$ & $\begin{array}{c}0.129 \\
(0)\end{array}$ & $\begin{array}{l}0.018 \\
(0.001) \\
\end{array}$ & $\begin{array}{l}0.147 \\
(0.001) \\
\end{array}$ & $\begin{array}{l}1.203 \\
(0.005) \\
\end{array}$ & $\begin{array}{c}0.346 \\
(0)\end{array}$ & 0.8813 \\
\hline \multicolumn{11}{|c|}{ CES + RRDA + ... } \\
\hline \multirow{3}{*}{\multicolumn{2}{|c|}{$\begin{array}{l}\text { CES } \\
\text { RRDA } \\
\text { CES }\end{array}$}} & 1 & $\begin{array}{l}0.269 \\
(\mathrm{NaN})\end{array}$ & $\begin{array}{c}31.285 \\
(0.047)\end{array}$ & $\begin{array}{c}0.299 \\
(0)\end{array}$ & $\begin{array}{l}0.669 \\
(0.001)\end{array}$ & $\begin{array}{c}12.829 \\
(0.027)\end{array}$ & $\begin{array}{c}0.66 \\
(0)\end{array}$ & $\begin{array}{l}1.003 \\
(0.001)\end{array}$ & \\
\hline & & 2 & $\begin{array}{c}0.664 \\
(0.05)\end{array}$ & $\begin{array}{l}4.373 \\
(0.041)\end{array}$ & $\begin{array}{l}0.167 \\
(0.001)\end{array}$ & $\underset{(0)}{0.07}$ & $\begin{array}{l}0.004 \\
(0.001)\end{array}$ & $\begin{array}{c}-0.345 \\
(0.002)\end{array}$ & $-\underset{(0)}{-1.092}$ & $\begin{array}{r}3500.23 \\
-3399.68\end{array}$ \\
\hline & & 3 & $\begin{array}{l}0.066 \\
(0.028)\end{array}$ & $\begin{array}{c}21.068 \\
(0.085)\end{array}$ & $\begin{array}{l}0.309 \\
(0.003)\end{array}$ & $\begin{array}{c}0.61 \\
(0.006)\end{array}$ & $\begin{array}{l}0.949 \\
(0.016)\end{array}$ & $\begin{array}{l}0.593 \\
(0.001)\end{array}$ & $\begin{array}{c}0.6 \\
(0.001)\end{array}$ & 0.8853 \\
\hline \multirow{3}{*}{$\begin{array}{l}\text { CES } \\
\text { RRDA } \\
\text { IneqAv }\end{array}$} & + & 1 & $\begin{array}{l}0.146 \\
(\mathrm{NaN})\end{array}$ & $\begin{array}{c}28.331 \\
(0.008)\end{array}$ & $\begin{array}{l}0.304 \\
(0)\end{array}$ & $\begin{array}{c}0.679 \\
(0)\end{array}$ & $\begin{array}{l}9.137 \\
(0.003)\end{array}$ & $\begin{array}{c}0.667 \\
(0)\end{array}$ & $\begin{array}{c}0.884 \\
(0)\end{array}$ & \\
\hline & + & 2 & $\begin{array}{l}0.659 \\
(0.051)\end{array}$ & $\begin{array}{l}4.24 \\
(0.06)\end{array}$ & $\begin{array}{l}0.198 \\
(0.002)\end{array}$ & $\begin{array}{l}0.101 \\
(0.001)\end{array}$ & $\begin{array}{c}0.039 \\
(0)\end{array}$ & $\begin{array}{c}-0.322 \\
(0.002)\end{array}$ & $\begin{array}{c}-1.019 \\
(0.004)\end{array}$ & $\begin{array}{r}3513.64 \\
-341155\end{array}$ \\
\hline & & 3 & $\begin{array}{l}0.195 \\
(0.042) \\
\end{array}$ & $\begin{array}{l}4.176 \\
(0.033) \\
\end{array}$ & $\begin{array}{l}0.272 \\
(0.002)\end{array}$ & $\begin{array}{l}0.035 \\
(0.001) \\
\end{array}$ & $\begin{array}{l}0.541 \\
(0.005) \\
\end{array}$ & $\begin{array}{c}0.033 \\
(0)\end{array}$ & $\begin{array}{c}0.044 \\
(0)\end{array}$ & 0.8839 \\
\hline \multirow{3}{*}{$\begin{array}{l}\text { CES } \\
\text { RRDA } \\
\text { RRDA }\end{array}$} & + & 1 & $\begin{array}{l}0.161 \\
(\mathrm{NaN})\end{array}$ & $\begin{array}{l}28.22 \\
(0.216)\end{array}$ & $\begin{array}{l}0.314 \\
(0.001)\end{array}$ & $\begin{array}{l}0.653 \\
(0.001)\end{array}$ & $\begin{array}{c}11.618 \\
(0.087)\end{array}$ & $\begin{array}{c}0.65 \\
(0)\end{array}$ & $\begin{array}{l}0.923 \\
(0.001)\end{array}$ & \\
\hline & + & 2 & $\begin{array}{l}0.637 \\
(0.057)\end{array}$ & $\begin{array}{l}4.237 \\
(0.061)\end{array}$ & $\begin{array}{c}0.16 \\
(0.002)\end{array}$ & $\begin{array}{l}0.127 \\
(0.001)\end{array}$ & $\begin{array}{c}0.03 \\
(0.001)\end{array}$ & $\begin{array}{c}-0.317 \\
(0.005)\end{array}$ & -1.076 & $\begin{array}{r}3531.01 \\
-341768\end{array}$ \\
\hline & & 3 & $\begin{array}{l}0.202 \\
(0.054) \\
\end{array}$ & $\begin{array}{l}3.001 \\
(0.002)\end{array}$ & $\begin{array}{c}0.196 \\
(0)\end{array}$ & $\begin{array}{c}0.148 \\
(0)\end{array}$ & $\begin{array}{c}0.13 \\
(0)\end{array}$ & $\begin{array}{c}-0.252 \\
(0)\end{array}$ & $\begin{array}{c}-0.572 \\
(0)\end{array}$ & 0.8832 \\
\hline \multirow{3}{*}{$\begin{array}{l}\text { CES } \\
\text { RRDA } \\
\text { ARDA }\end{array}$} & + & 1 & $\begin{array}{l}0.062 \\
(\mathrm{NaN})\end{array}$ & $\begin{array}{c}30.315 \\
(0.099)\end{array}$ & $\begin{array}{l}0.201 \\
(0.001)\end{array}$ & $\begin{array}{c}0.78 \\
(0.004)\end{array}$ & $\begin{array}{l}0.956 \\
(0.015)\end{array}$ & $\begin{array}{c}0.639 \\
(0)\end{array}$ & $\begin{array}{l}0.751 \\
(0.001)\end{array}$ & \\
\hline & 1 & 2 & $\begin{array}{l}0.484 \\
(0.055)\end{array}$ & $\begin{array}{l}5.213 \\
(0.015)\end{array}$ & $\begin{array}{l}0.138 \\
(0.001)\end{array}$ & $\begin{array}{l}0.097 \\
(0.001)\end{array}$ & $\begin{array}{c}0 \\
(0)\end{array}$ & $\begin{array}{c}-0.274 \\
(0.001)\end{array}$ & $\begin{array}{c}-1.001 \\
(0.007)\end{array}$ & $\begin{array}{r}3423.75 \\
-332016\end{array}$ \\
\hline & & 3 & $\begin{array}{l}0.454 \\
(0.055) \\
\end{array}$ & $\begin{array}{l}3.361 \\
(0.002) \\
\end{array}$ & $\begin{array}{l}0.133 \\
(0.001) \\
\end{array}$ & $\begin{array}{c}0.08 \\
(0)\end{array}$ & $\begin{array}{l}0.351 \\
(0.002) \\
\end{array}$ & $\begin{array}{c}0.805 \\
(0)\end{array}$ & $\begin{array}{c}0.334 \\
(0)\end{array}$ & 0.8943 \\
\hline \multicolumn{11}{|c|}{ Inequity Aversion + ARDA $+\ldots$} \\
\hline \multirow{2}{*}{\multicolumn{2}{|c|}{$\begin{array}{l}\text { IneqAv + } \\
\text { ARDA + } \\
\text { CES }\end{array}$}} & 1 & $\begin{array}{l}0.309 \\
(\mathrm{NaN})\end{array}$ & $\begin{array}{l}8.874 \\
(0.053)\end{array}$ & $\begin{array}{l}0.127 \\
(0.001)\end{array}$ & $\begin{array}{c}0.006 \\
(0)\end{array}$ & $\begin{array}{l}0.456 \\
(0.004)\end{array}$ & $\begin{array}{c}0.02 \\
(0)\end{array}$ & $\begin{array}{c}0.071 \\
(0)\end{array}$ & \\
\hline & & 2 & $\begin{array}{l}0.627 \\
(0.051)\end{array}$ & $\begin{array}{l}2.589 \\
(0.057) \\
\end{array}$ & $\begin{array}{l}0.129 \\
(0.002)\end{array}$ & $\begin{array}{l}0.018 \\
(0.005)\end{array}$ & $\begin{array}{c}0.147 \\
(0)\end{array}$ & $\begin{array}{l}1.203 \\
(0.012) \\
\end{array}$ & $\begin{array}{c}0.346 \\
(0)\end{array}$ & \\
\hline
\end{tabular}




\begin{tabular}{|c|c|c|c|c|c|c|c|c|c|}
\hline & Type & Share & $\lambda_{p}$ & $\rho_{1}$ & $\rho_{2}$ & $\lambda_{v}$ & $\alpha$ & $\beta$ & $I C E P E P,{ }^{2}$ \\
\hline & 3 & $\begin{array}{l}0.064 \\
(0.024)\end{array}$ & $\begin{array}{c}20.263 \\
(0.006)\end{array}$ & $\begin{array}{c}0.24 \\
(0)\end{array}$ & $\begin{array}{l}0.635 \\
(0.003)\end{array}$ & $\begin{array}{l}2.465 \\
(0.016)\end{array}$ & $\begin{array}{c}0.667 \\
(0)\end{array}$ & $\begin{array}{c}0.874 \\
(0)\end{array}$ & 0.8813 \\
\hline \multirow{3}{*}{$\begin{array}{l}\text { IneqAv + } \\
\text { ARDA + } \\
\text { IneqAv }\end{array}$} & 1 & $\begin{array}{c}0.32 \\
(N a N)\end{array}$ & $\begin{array}{l}8.342 \\
(0.005)\end{array}$ & $\begin{array}{c}0.131 \\
(0)\end{array}$ & $\begin{array}{c}0.013 \\
(0)\end{array}$ & $\begin{array}{l}0.515 \\
(0.001)\end{array}$ & $\begin{array}{c}0.002 \\
(0)\end{array}$ & $\begin{array}{c}0.078 \\
(0)\end{array}$ & \multirow{3}{*}{$\begin{array}{r}3517.12 \\
-3420.48 \\
0.8828 \\
\end{array}$} \\
\hline & 2 & $\begin{array}{l}0.627 \\
(0.052)\end{array}$ & $\begin{array}{l}3.179 \\
(0.018)\end{array}$ & $\begin{array}{l}0.141 \\
(0.001)\end{array}$ & $\begin{array}{l}0.004 \\
(0.001)\end{array}$ & $\begin{array}{c}0.102 \\
(0)\end{array}$ & $\begin{array}{l}1.006 \\
(0.005)\end{array}$ & $\begin{array}{c}0.353 \\
(0)\end{array}$ & \\
\hline & 3 & $\begin{array}{l}0.054 \\
(0.022) \\
\end{array}$ & $\begin{array}{l}0.636 \\
(0.002) \\
\end{array}$ & $\begin{array}{l}0.176 \\
(0.001) \\
\end{array}$ & $\begin{array}{l}0.029 \\
(0.002) \\
\end{array}$ & $\begin{array}{l}1.469 \\
(0.042) \\
\end{array}$ & $\begin{array}{l}0.001 \\
(0.001)\end{array}$ & $\begin{array}{c}0.091 \\
(0)\end{array}$ & \\
\hline \multirow{3}{*}{$\begin{array}{l}\text { IneqAv } \\
\text { ARDA } \\
\text { RRDA }\end{array}$} & 1 & $\begin{array}{c}0.073 \\
(\mathrm{NaN})\end{array}$ & $\begin{array}{c}0.894 \\
(0)\end{array}$ & $\begin{array}{l}0.157 \\
(0.003)\end{array}$ & $\begin{array}{l}0.011 \\
(0.001)\end{array}$ & $\begin{array}{l}0.498 \\
(0.011)\end{array}$ & $\begin{array}{c}0.004 \\
(0)\end{array}$ & $\begin{array}{l}0.056 \\
(0.001)\end{array}$ & \multirow{3}{*}{$\begin{array}{r}3404.32 \\
-3306.36 \\
0.8958\end{array}$} \\
\hline & 2 & $\begin{array}{l}0.447 \\
(0.055)\end{array}$ & $\begin{array}{l}4.608 \\
(0.078)\end{array}$ & $\begin{array}{l}0.148 \\
(0.001)\end{array}$ & $\begin{array}{l}0.024 \\
(0.002)\end{array}$ & $\begin{array}{l}0.326 \\
(0.005)\end{array}$ & $\begin{array}{l}0.726 \\
(0.011)\end{array}$ & $\begin{array}{c}0.372 \\
(0)\end{array}$ & \\
\hline & 3 & $\begin{array}{c}0.48 \\
(0.055) \\
\end{array}$ & $\begin{array}{l}5.659 \\
(0.034) \\
\end{array}$ & $\begin{array}{l}0.127 \\
(0.001) \\
\end{array}$ & $\begin{array}{l}0.094 \\
(0.001) \\
\end{array}$ & $\begin{array}{c}0 \\
(0.001) \\
\end{array}$ & $\begin{array}{c}-0.277 \\
(0.003) \\
\end{array}$ & $\begin{array}{c}-1 \\
(0.006)\end{array}$ & \\
\hline \multirow{3}{*}{$\begin{array}{l}\text { IneqAv + } \\
\text { ARDA + } \\
\text { ARDA }\end{array}$} & 1 & $\begin{array}{c}0.335 \\
(\mathrm{NaN})\end{array}$ & $\begin{array}{l}8.433 \\
(0.037)\end{array}$ & $\begin{array}{l}0.136 \\
(0.001)\end{array}$ & $\begin{array}{l}0.012 \\
(0.002)\end{array}$ & $\begin{array}{l}0.547 \\
(0.006)\end{array}$ & $\begin{array}{l}0.001 \\
(0.002)\end{array}$ & $\begin{array}{l}0.084 \\
(\mathrm{NaN})\end{array}$ & \multirow{3}{*}{$\begin{array}{r}3537 \\
-3425.01 \\
0.8823 \\
\end{array}$} \\
\hline & 2 & $\begin{array}{l}0.455 \\
(0.058)\end{array}$ & $\begin{array}{l}2.448 \\
(0.027)\end{array}$ & $\begin{array}{l}0.099 \\
(0.002)\end{array}$ & $\begin{array}{l}0.007 \\
(0.001)\end{array}$ & $\begin{array}{l}0.271 \\
(0.003)\end{array}$ & $\begin{array}{l}1.177 \\
(0.023)\end{array}$ & $\begin{array}{c}0.338 \\
(0)\end{array}$ & \\
\hline & 3 & $\begin{array}{c}0.21 \\
(0.046)\end{array}$ & $\begin{array}{c}4.461 \\
(0.06)\end{array}$ & $\begin{array}{c}0.198 \\
(0)\end{array}$ & $\begin{array}{l}0.071 \\
(0.002)\end{array}$ & $\begin{array}{l}0.003 \\
(0.001)\end{array}$ & $\begin{array}{c}0.942 \\
(0.01)\end{array}$ & $\begin{array}{l}0.368 \\
(0.001)\end{array}$ & \\
\hline \multicolumn{10}{|c|}{ RRDA + ARDA + ... } \\
\hline \multirow{3}{*}{$\begin{array}{l}\text { RRDA } \\
\text { ARDA } \\
\text { CES }\end{array}$} & 1 & $\begin{array}{c}0.484 \\
(\mathrm{NaN})\end{array}$ & $\begin{array}{l}5.213 \\
(0.021)\end{array}$ & $\begin{array}{l}0.138 \\
(0.002)\end{array}$ & $\begin{array}{l}0.097 \\
(0.001)\end{array}$ & $\begin{array}{c}0 \\
(0.001)\end{array}$ & $\begin{array}{c}-0.274 \\
(0.003)\end{array}$ & $\begin{array}{c}-1.001 \\
(0.005)\end{array}$ & \multirow{3}{*}{$\begin{array}{r}3423.74 \\
-3320.15 \\
0.8943\end{array}$} \\
\hline & 2 & $\begin{array}{l}0.454 \\
(0.055)\end{array}$ & $\begin{array}{l}3.361 \\
(0.018)\end{array}$ & $\begin{array}{l}0.133 \\
(0.003)\end{array}$ & $\begin{array}{c}0.08 \\
(0.001)\end{array}$ & $\begin{array}{l}0.351 \\
(0.002)\end{array}$ & $\begin{array}{c}0.805 \\
(0)\end{array}$ & $\begin{array}{c}0.334 \\
(0)\end{array}$ & \\
\hline & 3 & $\begin{array}{l}0.062 \\
(0.026) \\
\end{array}$ & $\begin{array}{c}30.315 \\
(0.168) \\
\end{array}$ & $\begin{array}{l}0.201 \\
(0.001)\end{array}$ & $\begin{array}{c}0.78 \\
(0.003)\end{array}$ & $\begin{array}{l}0.956 \\
(0.002)\end{array}$ & $\begin{array}{c}0.639 \\
(0)\end{array}$ & $\begin{array}{l}0.751 \\
(0.003) \\
\end{array}$ & \\
\hline \multirow{3}{*}{$\begin{array}{l}\text { RRDA } \\
\text { ARDA } \\
\text { IneqAv }\end{array}$} & 1 & $\begin{array}{c}0.481 \\
(N a N)\end{array}$ & $\begin{array}{l}5.653 \\
(0.027)\end{array}$ & $\begin{array}{l}0.127 \\
(0.001)\end{array}$ & $\begin{array}{c}0.094 \\
(0)\end{array}$ & $\begin{array}{c}0 \\
(0)\end{array}$ & $\begin{array}{c}-0.277 \\
(0.002)\end{array}$ & $\begin{array}{c}-0.996 \\
(0)\end{array}$ & \multirow{3}{*}{$\begin{array}{r}3405.07 \\
-3306.89 \\
0.8958\end{array}$} \\
\hline & 2 & $\begin{array}{l}0.447 \\
(0.055)\end{array}$ & $\begin{array}{l}4.604 \\
(0.029)\end{array}$ & $\begin{array}{c}0.148 \\
(0)\end{array}$ & $\begin{array}{l}0.024 \\
(0.001)\end{array}$ & $\begin{array}{l}0.328 \\
(0.002)\end{array}$ & $\begin{array}{l}0.732 \\
(0.003)\end{array}$ & $\begin{array}{c}0.36 \\
(0)\end{array}$ & \\
\hline & 3 & $\begin{array}{l}0.072 \\
(0.023)\end{array}$ & $\begin{array}{l}0.894 \\
(0.011) \\
\end{array}$ & $\begin{array}{l}0.157 \\
(0.006)\end{array}$ & $\begin{array}{l}0.011 \\
(0.003)\end{array}$ & $\begin{array}{c}0.498 \\
(0.01)\end{array}$ & $\begin{array}{c}0.004 \\
(0)\end{array}$ & $\begin{array}{l}0.056 \\
(0.001)\end{array}$ & \\
\hline \multirow{3}{*}{$\begin{array}{l}\text { RRDA } \\
\text { ARDA } \\
\text { RRDA }\end{array}$} & 1 & $\begin{array}{c}0.456 \\
(N a N)\end{array}$ & $\begin{array}{c}5.649 \\
(0.08)\end{array}$ & $\begin{array}{l}0.133 \\
(0.002)\end{array}$ & $\begin{array}{l}0.077 \\
(0.003)\end{array}$ & $\begin{array}{c}0 \\
(0.001)\end{array}$ & $\begin{array}{c}-0.275 \\
(0.005)\end{array}$ & $\begin{array}{c}-0.986 \\
(0.008)\end{array}$ & \multirow{3}{*}{$\begin{array}{r}3422.73 \\
-3310.86 \\
0.8953\end{array}$} \\
\hline & 2 & $\begin{array}{l}0.368 \\
(0.052)\end{array}$ & $\begin{array}{l}3.362 \\
(0.033)\end{array}$ & $\begin{array}{l}0.117 \\
(0.007)\end{array}$ & $\begin{array}{l}0.007 \\
(0.011)\end{array}$ & $\begin{array}{l}0.429 \\
(0.002)\end{array}$ & $\begin{array}{l}0.825 \\
(0.006)\end{array}$ & $\begin{array}{c}0.339 \\
(0)\end{array}$ & \\
\hline & 3 & $\begin{array}{l}0.176 \\
(0.047) \\
\end{array}$ & $\begin{array}{l}2.879 \\
(0.002) \\
\end{array}$ & $\begin{array}{c}0.205 \\
(0)\end{array}$ & $\begin{array}{c}0.126 \\
(0)\end{array}$ & $\begin{array}{c}0.014 \\
(0)\end{array}$ & $\begin{array}{c}-0.269 \\
(0)\end{array}$ & $\begin{array}{c}-0.652 \\
(0.001) \\
\end{array}$ & \\
\hline \multirow{3}{*}{$\begin{array}{l}\text { RRDA } \\
\text { ARDA } \\
\text { ARDA }\end{array}$} & 1 & $\begin{array}{c}0.483 \\
(\mathrm{NaN})\end{array}$ & $\begin{array}{c}5.297 \\
(0.04)\end{array}$ & $\begin{array}{l}0.129 \\
(0.001)\end{array}$ & $\begin{array}{l}0.085 \\
(0.003)\end{array}$ & $\begin{array}{c}0 \\
0\end{array}$ & $\begin{array}{c}-0.263 \\
(0.003)\end{array}$ & $\begin{array}{c}-0.99 \\
(0.004)\end{array}$ & \multirow{3}{*}{$\begin{array}{r}3437.96 \\
-3326.52 \\
0.8936\end{array}$} \\
\hline & 2 & $\begin{array}{l}0.316 \\
(0.056)\end{array}$ & $\begin{array}{l}3.312 \\
(0.001)\end{array}$ & $\begin{array}{c}0.114 \\
(0)\end{array}$ & $\begin{array}{c}0.164 \\
(0)\end{array}$ & $\begin{array}{c}0.66 \\
(0.028)\end{array}$ & $\begin{array}{c}0.79 \\
(0.146)\end{array}$ & $\begin{array}{c}0.337 \\
(0)\end{array}$ & \\
\hline & 3 & $\begin{array}{l}0.201 \\
(0.049)\end{array}$ & $\begin{array}{l}2.677 \\
(0.011)\end{array}$ & $\begin{array}{c}0.168 \\
(0)\end{array}$ & $\begin{array}{l}0.034 \\
(0.002)\end{array}$ & $\begin{array}{l}0.084 \\
(0.001)\end{array}$ & $\begin{array}{l}0.927 \\
(0.022)\end{array}$ & $\begin{array}{c}0.353 \\
(0)\end{array}$ & \\
\hline
\end{tabular}

Table 7: Four-type mixed model

\begin{tabular}{|c|c|c|c|c|c|c|c|c|c|}
\hline & Type & Share & $\overline{\lambda_{p}}$ & $\rho_{1}$ & $\rho_{2}$ & $\overline{\lambda_{v}}$ & $\alpha$ & $\bar{\beta}$ & $\overline{I C L / L L / R^{2}}$ \\
\hline \multicolumn{10}{|c|}{ CES + IneqAv + RRDA + ARDA } \\
\hline CES + & 1 & $\begin{array}{l}0.061 \\
(\text { NaN })\end{array}$ & $\begin{array}{c}17.001 \\
(0.07)\end{array}$ & $\begin{array}{l}0.353 \\
(0.001)\end{array}$ & $\begin{array}{l}0.646 \\
(0.003)\end{array}$ & $\begin{array}{l}5.419 \\
(0.006)\end{array}$ & $\begin{array}{c}0.676 \\
(0)\end{array}$ & $\begin{array}{l}0.791 \\
(0.001)\end{array}$ & \\
\hline $\begin{array}{l}\text { IneqAv + } \\
\text { RRDA + }\end{array}$ & 2 & $\begin{array}{l}0.136 \\
(0.038)\end{array}$ & $\begin{array}{l}8.371 \\
(0.155)\end{array}$ & $\begin{array}{l}0.156 \\
(0.003)\end{array}$ & $\begin{array}{l}0.002 \\
(0.004)\end{array}$ & $\begin{array}{l}0.439 \\
(0.001)\end{array}$ & $\begin{array}{l}0.014 \\
(0.001)\end{array}$ & $\begin{array}{l}0.058 \\
(0.001)\end{array}$ & \\
\hline ARDA & 3 & $\begin{array}{l}0.419 \\
(0.054)\end{array}$ & $\begin{array}{l}5.151 \\
(0.068)\end{array}$ & $\begin{array}{l}0.131 \\
(0.001)\end{array}$ & $\begin{array}{l}0.094 \\
(0.002)\end{array}$ & $\begin{array}{c}0 \\
(0.001)\end{array}$ & $\begin{array}{c}-0.264 \\
(0.002)\end{array}$ & $\frac{-1.002}{(0.009)}$ & \\
\hline
\end{tabular}




\begin{tabular}{|c|c|c|c|c|c|c|c|c|}
\hline Type & Share & $\lambda_{p}$ & $\rho_{1}$ & $\rho_{2}$ & $\lambda_{v}$ & $\alpha$ & $\beta$ & $I C \not 44 Q 7 R^{2}$ \\
\hline 4 & $\begin{array}{l}0.385 \\
(0.057)\end{array}$ & $\begin{array}{l}3.469 \\
(0.076)\end{array}$ & $\begin{array}{l}0.125 \\
(0.001)\end{array}$ & $\begin{array}{l}0.097 \\
(0.001)\end{array}$ & $\begin{array}{l}0.323 \\
(0.004)\end{array}$ & $\begin{array}{l}0.833 \\
(0.008)\end{array}$ & $\begin{array}{c}0.334 \\
(0)\end{array}$ & 0.898 \\
\hline
\end{tabular}

Table 8: Heterogenous models (proposer and voters may have different preferences). Does not improve goodness-of-fit

\begin{tabular}{|c|c|c|c|c|c|c|c|c|c|}
\hline & $\overline{\bar{\lambda}}$ & $\rho_{1}$ & $\rho_{2}$ & $\overline{\bar{\lambda}}$ & $\alpha_{\text {Prop }}$ & $\beta_{\text {Prop }}$ & $\alpha_{\text {Vot }}$ & $\beta_{\mathrm{Vot}}$ & $\overline{I C L / L L / R^{2}}$ \\
\hline \multicolumn{10}{|c|}{ Proposer CES + Voter ... } \\
\hline CES & $\begin{array}{c}27.488 \\
(0.073)\end{array}$ & $\begin{array}{l}0.216 \\
(0.001)\end{array}$ & $\begin{array}{l}0.641 \\
(0.002)\end{array}$ & $\begin{array}{l}0.963 \\
(0.009)\end{array}$ & $\begin{array}{l}0.636 \\
(0.001)\end{array}$ & $\begin{array}{c}0.777 \\
(0)\end{array}$ & $\underset{(0)}{0.628}$ & $\begin{array}{l}0.777 \\
(0)\end{array}$ & $\begin{array}{r}3995.85 \\
-3965.56 \\
0.7947\end{array}$ \\
\hline IneqAv & $\begin{array}{c}22.693 \\
(0.041)\end{array}$ & $\underset{(0)}{0.178}$ & $\begin{array}{l}0.618 \\
(0.002)\end{array}$ & $\begin{array}{c}0.47 \\
(0)\end{array}$ & $\begin{array}{l}0.605 \\
(0.002)\end{array}$ & $\begin{array}{l}0.911 \\
(0.002)\end{array}$ & $\begin{array}{c}0.009 \\
(0)\end{array}$ & $\begin{array}{l}0.078 \\
(0.001)\end{array}$ & $\begin{array}{r}3935.75 \\
-3905.46 \\
0.807\end{array}$ \\
\hline RRDA & $\begin{array}{l}0.844 \\
(0.01)\end{array}$ & $\begin{array}{l}0.001 \\
(0.001)\end{array}$ & $\begin{array}{l}0.566 \\
(0.008)\end{array}$ & $\begin{array}{c}0.02 \\
(0.001)\end{array}$ & $\begin{array}{c}0.844 \\
(0)\end{array}$ & $\begin{array}{l}0.827 \\
(0.002)\end{array}$ & $\begin{array}{l}0.043 \\
(0.001)\end{array}$ & $\begin{array}{c}-0.198 \\
(0)\end{array}$ & $\begin{array}{r}4163.89 \\
-4133.6 \\
0.756\end{array}$ \\
\hline ARDA & $\begin{array}{l}0.853 \\
(0.008)\end{array}$ & $\begin{array}{l}0.001 \\
(0.002)\end{array}$ & $\begin{array}{l}0.583 \\
(0.016)\end{array}$ & $\begin{array}{c}0.22 \\
(0.002)\end{array}$ & $\begin{array}{l}0.833 \\
(0.005)\end{array}$ & $\begin{array}{l}0.804 \\
(0.007)\end{array}$ & $\begin{array}{l}1.105 \\
(0.018)\end{array}$ & $\begin{array}{c}0.299 \\
(0)\end{array}$ & $\begin{array}{r}4099.38 \\
-4069.09 \\
0.7716\end{array}$ \\
\hline \multicolumn{10}{|c|}{ Proposer IneqAv + Voter ... } \\
\hline CES & $\begin{array}{l}2.983 \\
(0.008)\end{array}$ & $\begin{array}{l}0.195 \\
(0.001)\end{array}$ & $\underset{(0)}{0.021}$ & $\underset{(0)}{0.822}$ & $\begin{array}{c}0.17 \\
(0.001)\end{array}$ & $\underset{(0)}{0.166}$ & $\begin{array}{l}0.501 \\
(0.001)\end{array}$ & $\begin{array}{c}0.732 \\
(0)\end{array}$ & $\begin{array}{r}3740.52 \\
-3710.23 \\
0.8421\end{array}$ \\
\hline IneqAv & $\begin{array}{c}4.042 \\
(0)\end{array}$ & $\underset{(0)}{0.16}$ & $\begin{array}{c}0.013 \\
(0)\end{array}$ & $\underset{(0)}{0.527}$ & $\begin{array}{c}0.085 \\
(0)\end{array}$ & $\underset{(0)}{0.052}$ & $\begin{array}{c}0 \\
(0)\end{array}$ & $\begin{array}{c}0.052 \\
(0)\end{array}$ & $\begin{array}{r}3839.31 \\
-3809.02 \\
0.8252\end{array}$ \\
\hline RRDA & $\begin{array}{l}6.097 \\
(0.016)\end{array}$ & $\begin{array}{c}0.143 \\
(0)\end{array}$ & $\begin{array}{c}0.065 \\
(0)\end{array}$ & $\begin{array}{c}0.355 \\
(0)\end{array}$ & $\begin{array}{l}0.167 \\
(0.001)\end{array}$ & $\begin{array}{c}0.269 \\
(0)\end{array}$ & $\begin{array}{c}0.099 \\
(0)\end{array}$ & $\underset{(0)}{0.115}$ & $\begin{array}{r}3708.69 \\
-3678.4 \\
0.8472\end{array}$ \\
\hline ARDA & $\begin{array}{l}6.874 \\
(0.072)\end{array}$ & $\begin{array}{l}0.162 \\
(0.002)\end{array}$ & $\begin{array}{l}0.133 \\
(0.001)\end{array}$ & $\begin{array}{l}0.258 \\
(0.003)\end{array}$ & $\begin{array}{c}0.02 \\
(0.001)\end{array}$ & $\underset{(0)}{0.336}$ & $\begin{array}{c}0.868 \\
(0)\end{array}$ & $\underset{(0)}{0.131}$ & $\begin{array}{r}3547.13 \\
-3516.84 \\
0.8706\end{array}$ \\
\hline \multicolumn{10}{|c|}{ Proposer RRDA + Voter ... } \\
\hline CES & $\begin{array}{l}1.498 \\
(0.017)\end{array}$ & $\begin{array}{l}0.158 \\
(0.001)\end{array}$ & $\begin{array}{l}0.009 \\
(0.005)\end{array}$ & $\begin{array}{c}0 \\
(\mathrm{NaN})\end{array}$ & $\begin{array}{c}-0.252 \\
(0.003)\end{array}$ & $\begin{array}{c}-1.662 \\
(0.007)\end{array}$ & $\begin{array}{c}0.437 \\
(0)\end{array}$ & $\begin{array}{l}0.555 \\
(0.003)\end{array}$ & $\begin{array}{r}3748.12 \\
-3718.2 \\
0.8408\end{array}$ \\
\hline IneqAv & $\begin{array}{l}2.834 \\
(0.002)\end{array}$ & $\begin{array}{l}0.216 \\
(0.001)\end{array}$ & $\begin{array}{l}0.224 \\
(0.001)\end{array}$ & $\underset{(0)}{0.175}$ & $\begin{array}{c}-0.204 \\
(0.002)\end{array}$ & $\begin{array}{c}-0.612 \\
(0.002)\end{array}$ & $\begin{array}{l}0.231 \\
(0.001)\end{array}$ & $\begin{array}{c}0 \\
(0)\end{array}$ & $\begin{array}{r}3835.47 \\
-3805.17 \\
0.8259\end{array}$ \\
\hline RRDA & $\begin{array}{c}3.039 \\
(0)\end{array}$ & $\begin{array}{l}0.187 \\
(0.001)\end{array}$ & $\begin{array}{l}0.159 \\
(0.001)\end{array}$ & $\begin{array}{l}0.135 \\
(0.001)\end{array}$ & $\begin{array}{c}-0.273 \\
(0.003)\end{array}$ & $\begin{array}{c}-0.678 \\
(0.003)\end{array}$ & $\begin{array}{c}-0.256 \\
(0)\end{array}$ & $-\underset{(0)}{-0.504}$ & $\begin{array}{r}3650.13 \\
-3619.23 \\
0.8562\end{array}$ \\
\hline ARDA & $\begin{array}{l}2.458 \\
(0.001)\end{array}$ & $\begin{array}{c}0.156 \\
(0)\end{array}$ & $\begin{array}{l}0.182 \\
(0.002)\end{array}$ & $\begin{array}{l}0.183 \\
(0.001)\end{array}$ & $\begin{array}{c}-0.164 \\
(0.001)\end{array}$ & $\begin{array}{c}-0.797 \\
(0.005)\end{array}$ & $\begin{array}{l}1.186 \\
(0.008)\end{array}$ & $\begin{array}{c}0.375 \\
(0)\end{array}$ & $\begin{array}{r}3605.1 \\
-3574.81 \\
0.8627\end{array}$ \\
\hline
\end{tabular}




\begin{tabular}{|c|c|c|c|c|c|c|c|c|c|}
\hline & $\lambda_{p}$ & $\rho_{1}$ & $\rho_{2}$ & $\lambda_{v}$ & $\alpha_{\text {Prop }}$ & $\beta_{\text {Prop }}$ & $\alpha_{\mathrm{Vot}}$ & $\beta_{\mathrm{Vot}}$ & $I C L / L L / R^{2}$ \\
\hline \multicolumn{10}{|c|}{ Proposer ARDA + Voter ... } \\
\hline \multirow[b]{2}{*}{ CES } & \multirow[b]{2}{*}{$\begin{array}{l}2.165 \\
(0.022)\end{array}$} & \multirow[b]{2}{*}{$\begin{array}{c}0.088 \\
(0)\end{array}$} & \multirow[b]{2}{*}{$\begin{array}{l}0.002 \\
(0.002)\end{array}$} & \multirow[b]{2}{*}{$\begin{array}{c}-0.001 \\
(\mathrm{NaN})\end{array}$} & \multirow[b]{2}{*}{$\begin{array}{l}1.46 \\
(0.01) \\
\end{array}$} & \multirow[b]{2}{*}{$\begin{array}{l}0.009 \\
(0.001)\end{array}$} & \multirow[b]{2}{*}{$\begin{array}{l}0.433 \\
(0.003)\end{array}$} & \multirow[b]{2}{*}{$\begin{array}{c}0.79 \\
(0.002)\end{array}$} & 3750.57 \\
\hline & & & & & & & & & $\begin{array}{r}-3725.76 \\
0.8396\end{array}$ \\
\hline \multirow{3}{*}{ IneqAv } & \multirow{3}{*}{$\begin{array}{l}3.535 \\
(0.013)\end{array}$} & \multirow{3}{*}{$\underset{(0)}{0.092}$} & \multirow{3}{*}{$\begin{array}{l}0.384 \\
(0.002)\end{array}$} & \multirow{3}{*}{$\begin{array}{l}0.019 \\
(0.001)\end{array}$} & \multirow{3}{*}{$\begin{array}{l}0.983 \\
(0.004)\end{array}$} & \multirow{3}{*}{$\begin{array}{c}0.327 \\
(0)\end{array}$} & \multirow{3}{*}{$\begin{array}{c}0.03 \\
(0)\end{array}$} & \multirow{3}{*}{$\begin{array}{c}0.107 \\
(0)\end{array}$} & 3910.23 \\
\hline & & & & & & & & & -3879.94 \\
\hline & & & & & & & & & 0.812 \\
\hline \multirow{3}{*}{ RRDA } & \multirow{3}{*}{$\begin{array}{l}2.763 \\
(0.009)\end{array}$} & \multirow{3}{*}{$\begin{array}{l}0.112 \\
(0.002)\end{array}$} & \multirow{3}{*}{$\begin{array}{l}0.311 \\
(0.003)\end{array}$} & \multirow{3}{*}{$\begin{array}{c}0 \\
(0)\end{array}$} & \multirow{3}{*}{$\begin{array}{l}1.218 \\
(0.01)\end{array}$} & \multirow{3}{*}{$\begin{array}{l}0.331 \\
(0.002)\end{array}$} & \multirow{3}{*}{$\begin{array}{l}0.797 \\
(0.003)\end{array}$} & & 3784.21 \\
\hline & & & & & & & & \multirow{2}{*}{$\begin{array}{l}0.108 \\
(0.001)\end{array}$} & -3753.92 \\
\hline & & & & & & & & & 0.8349 \\
\hline \multirow{3}{*}{ ARDA } & \multirow{3}{*}{$\begin{array}{l}3.814 \\
(0.086)\end{array}$} & \multirow{3}{*}{$\begin{array}{l}0.097 \\
(0.002)\end{array}$} & \multirow{3}{*}{$\begin{array}{l}0.235 \\
(0.006)\end{array}$} & \multirow{3}{*}{$\begin{array}{c}0.12 \\
(0.005)\end{array}$} & \multirow{3}{*}{$\begin{array}{l}0.919 \\
(0.03)\end{array}$} & \multirow{3}{*}{$\begin{array}{l}0.284 \\
(0.003)\end{array}$} & \multirow{3}{*}{$\begin{array}{l}1.985 \\
(0.033)\end{array}$} & \multirow{3}{*}{$\begin{array}{l}0.4 \\
(0)\end{array}$} & 3597.39 \\
\hline & & & & & & & & & -3567.1 \\
\hline & & & & & & & & & 0.8638 \\
\hline
\end{tabular}


Table 9: Estimates for models with time-dependent parameters. All parameters $x \in\{\lambda, \alpha, \beta\}$ have an initial value and a time dependency parameter $\kappa_{x}$; the parameter value in game $g$ is $x+\kappa_{x} \cdot g$. The goodness-of-fit does not improve significantly over the constant models, suggesting that parameters do not change significantly.

\begin{tabular}{|c|c|c|c|c|c|c|c|c|c|c|c|c|c|}
\hline & Type & Share & $\bar{\lambda}_{p}$ & $\kappa_{p}$ & $\rho_{1}$ & $\rho_{2}$ & $\overline{\lambda_{v}}$ & $\kappa_{v}$ & $\alpha$ & $\kappa_{\alpha}$ & $\bar{\beta}$ & $\kappa_{\beta}$ & $I C L / L L / R^{2}$ \\
\hline & & & & & & & & & & & & & 3941.66 \\
\hline CES & 1 & $\begin{array}{c}1 \\
(N a N)\end{array}$ & $\begin{array}{l}8.614 \\
(0.002)\end{array}$ & $\begin{array}{c}-7.262 \\
(0.064)\end{array}$ & $\begin{array}{c}0.169 \\
(0)\end{array}$ & $\begin{array}{l}0.082 \\
(0.001)\end{array}$ & $\begin{array}{l}0.959 \\
(0.004)\end{array}$ & $\begin{array}{c}-0.373 \\
(0.001)\end{array}$ & $\begin{array}{l}0.248 \\
(0.001)\end{array}$ & $\begin{array}{l}0.339 \\
(0.002)\end{array}$ & $\begin{array}{c}0.91 \\
(0)\end{array}$ & $\underset{(0)}{0.028}$ & $\begin{array}{r}-3903.8 \\
0.8074\end{array}$ \\
\hline & & & & & & & & & & & & & 3783.07 \\
\hline IneqAv & 1 & $\begin{array}{c}1 \\
(N a N)\end{array}$ & $\begin{array}{l}4.235 \\
(\mathrm{NaN})\end{array}$ & $\begin{array}{c}-0.742 \\
(\text { NaN })\end{array}$ & $\begin{array}{l}0.168 \\
(\mathrm{NaN})\end{array}$ & $\begin{array}{l}0.018 \\
(\mathrm{NaN})\end{array}$ & $\begin{array}{l}0.709 \\
(\mathrm{NaN})\end{array}$ & $\begin{array}{l}-0.467 \\
(0.013)\end{array}$ & $\begin{array}{l}0.001 \\
(N a N)\end{array}$ & $\begin{array}{c}-0.013 \\
(\text { NaN })\end{array}$ & $\begin{array}{l}0.062 \\
(\text { NaN })\end{array}$ & $\begin{array}{c}-0.014 \\
(\text { NaN })\end{array}$ & $\begin{array}{r}-3745.21 \\
0.8364\end{array}$ \\
\hline & & & & & & & & & & & & & 3672.26 \\
\hline RRDA & 1 & $\begin{array}{c}1 \\
(N a N)\end{array}$ & $\begin{array}{l}3.163 \\
(0.003)\end{array}$ & $\begin{array}{c}-0.483 \\
(0)\end{array}$ & $\begin{array}{c}0.194 \\
(0)\end{array}$ & $\begin{array}{c}0.118 \\
(0)\end{array}$ & $\begin{array}{c}0.057 \\
(0)\end{array}$ & $\begin{array}{c}0.053 \\
(0)\end{array}$ & $\begin{array}{c}-0.379 \\
(0)\end{array}$ & $\begin{array}{c}-0.087 \\
(0)\end{array}$ & $\begin{array}{c}-0.899 \\
(0)\end{array}$ & $\begin{array}{c}-0.068 \\
(0)\end{array}$ & $\begin{array}{r}-3634.39 \\
0.854\end{array}$ \\
\hline ARDA & 1 & $\begin{array}{c}1 \\
\text { (NaN) }\end{array}$ & $\begin{array}{l}4.045 \\
(0.005)\end{array}$ & $\begin{array}{c}-1.087 \\
(0.005)\end{array}$ & $\begin{array}{c}0.109 \\
(0)\end{array}$ & $\begin{array}{c}0.19 \\
(0.001)\end{array}$ & $\underset{(0)}{0.204}$ & $\underset{(0)}{-0.058}$ & $\begin{array}{l}0.948 \\
(0.003)\end{array}$ & $\underset{(0)}{0.041}$ & $\underset{(0)}{0.37}$ & $\underset{(0)}{0.01}$ & $\begin{array}{r}3632.64 \\
-3594.77 \\
0.8598\end{array}$ \\
\hline \multirow[t]{2}{*}{$\begin{array}{l}\text { CES + } \\
\text { IneqAv }\end{array}$} & 1 & $\begin{array}{l}0.314 \\
(\mathrm{NaN})\end{array}$ & $\begin{array}{l}32.426 \\
(0.008)\end{array}$ & $\begin{array}{l}0.025 \\
(0.001)\end{array}$ & $\begin{array}{c}0.354 \\
(0)\end{array}$ & $\begin{array}{c}0.617 \\
(0)\end{array}$ & $\begin{array}{l}13.038 \\
(0.001)\end{array}$ & $\begin{array}{c}-0.022 \\
(0)\end{array}$ & $\begin{array}{c}0.667 \\
(0)\end{array}$ & $\begin{array}{c}-0.004 \\
(0.001)\end{array}$ & $\begin{array}{c}0.874 \\
(0)\end{array}$ & $\begin{array}{c}0.11 \\
(0)\end{array}$ & \multirow{2}{*}{$\begin{array}{r}3685.83 \\
-3590.88 \\
0.8604 \\
\end{array}$} \\
\hline & 2 & $\begin{array}{l}0.686 \\
(0.047)\end{array}$ & $\begin{array}{l}6.091 \\
(0.059)\end{array}$ & $\begin{array}{l}0.027 \\
(0.003)\end{array}$ & $\begin{array}{l}0.148 \\
(0.001)\end{array}$ & $\begin{array}{l}0.002 \\
(0.001)\end{array}$ & $\begin{array}{l}0.414 \\
(0.005)\end{array}$ & $\begin{array}{l}0.015 \\
(0.002)\end{array}$ & $\begin{array}{l}0.014 \\
(0.001)\end{array}$ & $\begin{array}{c}-0.028 \\
(0.002)\end{array}$ & $\begin{array}{l}0.066 \\
(0.001)\end{array}$ & $\begin{array}{l}0.011 \\
(0.001)\end{array}$ & \\
\hline \multirow{2}{*}{$\begin{array}{l}\text { RRDA } \\
+ \\
\text { ARDA }\end{array}$} & 1 & $\begin{array}{l}0.528 \\
(N a N)\end{array}$ & $\begin{array}{l}5.443 \\
(0.022)\end{array}$ & $\begin{array}{c}-0.002 \\
(0.001)\end{array}$ & $\begin{array}{c}0.133 \\
(0)\end{array}$ & $\begin{array}{l}0.103 \\
(0.001)\end{array}$ & $\begin{array}{c}0 \\
(0.001)\end{array}$ & $\begin{array}{c}-0.006 \\
(0)\end{array}$ & $\begin{array}{c}-0.268 \\
(0.002)\end{array}$ & $\begin{array}{l}0.002 \\
(0.001)\end{array}$ & $\begin{array}{c}-1.004 \\
(0)\end{array}$ & $\begin{array}{c}-0.001 \\
(0.001)\end{array}$ & \multirow{2}{*}{$\begin{array}{r}3432.46 \\
-3335.6 \\
0.8926\end{array}$} \\
\hline & 2 & $\begin{array}{l}0.472 \\
(0.054)\end{array}$ & $\begin{array}{c}3.235 \\
(0.01)\end{array}$ & $\begin{array}{l}0.031 \\
(0.001)\end{array}$ & $\begin{array}{c}0.12 \\
(0.001)\end{array}$ & $\begin{array}{l}0.049 \\
(0.001)\end{array}$ & $\begin{array}{l}0.307 \\
(0.003)\end{array}$ & $\begin{array}{l}0.301 \\
(0.001)\end{array}$ & $\begin{array}{l}0.789 \\
(0.001)\end{array}$ & $\begin{array}{c}-0.004 \\
(0.001)\end{array}$ & $\begin{array}{c}0.338 \\
(0)\end{array}$ & $-\underset{(0)}{-0.004}$ & \\
\hline
\end{tabular}

